\title{
MODERNIZAÇÃO E DUALISMO TECNOLOGICO NA AGRICULTURA: UMA ANÁLISE APOIADA EM CURVAS DE OFERTA
}

\author{
JACKSON ORNELAS MENDONCQA
}

\author{
Orientador: EVARISTO MARZABAL NEVES
}

\begin{abstract}
Dissertação apresentada à Escola Superior de Agricultura "Luiz de Queiroz" da Universidade de São Paulo, para obtenção do título de Mestre em Economia Agrária.
\end{abstract}

PIRACICABA

Estado de São Paulo, Brasil Junho, 1980 
ii.

A Diana, Carolina e Joana 


\section{AGRADE CIMENTOS}

Muitas pessoas contribuiram de distintas formas, em períodos diferentes, para a realização deste trabalho e a elas desejamos manifestar os nossos agradecimentos. Entretan to, àqueles que mais diretamente emprestaram a sua colaboração, desejamos fazê-1o nominalmente:

- Ao prof. Evaristo Marzabal Neves, pela orientação, estímulos e atenção dedicados.

- Ao prof. Rubens Valentini, pelas orientações re cebidas, notadamente na fase da elaboração do projeto.

- Ao Dr. Edward Schuh e aos profs. Geraldo Camargo e Fernando Peres, pelas valiosas sugestões após a leitura da primeira versão deste trabalho.

- Aos profs. Rodolfo Hoffmann e Flávio A. Pinheiro, pelas contribuições apresentadas após a leitura da segunda versão e que foram decisivas para a conclusão do trabalho.

- Ao colega Richard Domingues Dulley, que no I.E.A. ajudou na decodificação dos dados.

- Aos colegas do Centro de Planejamento da Bahia, especialmente, Lucia Mota, Waldeck, Gey, Maciel, 
Virginia, Massilon, Betinho, Zefa, Valmira, Socorro, Eliane, Jacyra e Grazia, pelo apoio e pe 1a compreensão ao assumirem algumas tarefas para que pudéssemos nos dedicar mais a este traba 1ho.

- Á Arquiteta Maria de Lourdes e a Jonas Negri, responsáveis pelos desenhos em nankin.

- Aos colegas da Escola de Agronomia, em Cruz das Almas, pelo estímulo sempre renovado.

- Aos funcionárïos do Departamento de Economia e Sociologia Rural da ESALQ/USP, pela boa vontade, sempre demonstrada, em colaborar.

- À Fundação FORD e à EMBRAPA, pelo auxílios financeiros concedidos.

- Finalmente, ao Antonio José, pelo excelente tra balho de datilografia. 
LISTA DE TABELAS $\ldots \ldots \ldots \ldots \ldots \ldots \ldots \ldots \ldots \ldots \ldots \ldots \ldots \ldots \ldots \ldots$

LISTA DE FIGURAS $\ldots \ldots \ldots \ldots \ldots \ldots \ldots \ldots \ldots \ldots \ldots \ldots \ldots \ldots \ldots \ldots \ldots \ldots$

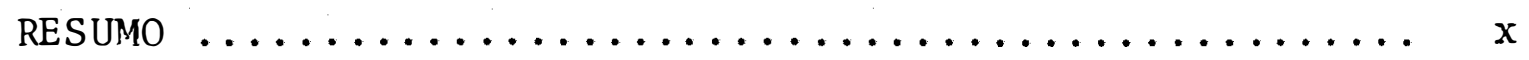

1. INTRODUÇÃo $\ldots \ldots \ldots \ldots \ldots \ldots \ldots \ldots \ldots \ldots \ldots \ldots \ldots \ldots \ldots \ldots \ldots \ldots$

2. REVISÃO BIBLIOGRÁFICA $\ldots \ldots \ldots \ldots \ldots \ldots \ldots \ldots \ldots$

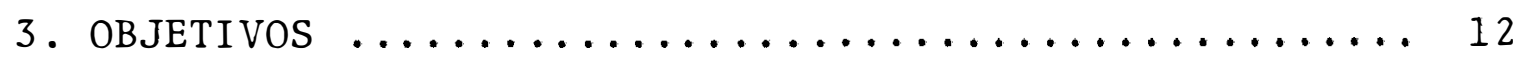

4. MAterial e método $\ldots \ldots \ldots \ldots \ldots \ldots \ldots \ldots \ldots \ldots \ldots \ldots$

4.1. Hipóteses sobre as curvas de oferta ........ 17

4.2. Método de estimação ................. 25

4.3. Descrição das variāveis $\ldots \ldots \ldots \ldots \ldots \ldots \ldots \ldots \ldots \ldots$

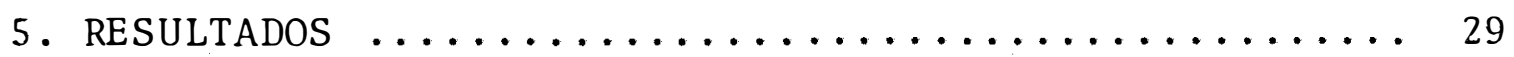

6. CONCLUSÕES $\ldots \ldots \ldots \ldots \ldots \ldots \ldots \ldots \ldots \ldots \ldots \ldots \ldots \ldots \ldots \ldots \ldots \ldots$

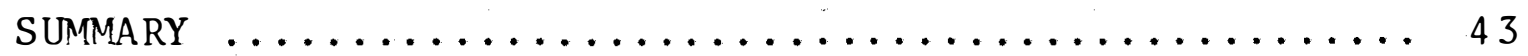

Literatura CitAdA $\ldots \ldots \ldots \ldots \ldots \ldots \ldots \ldots \ldots \ldots \ldots$

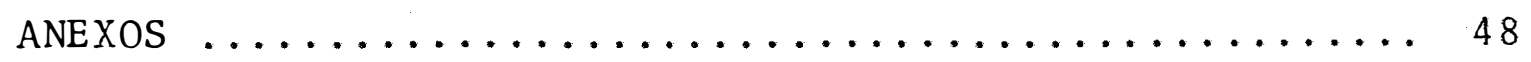




\section{LISTA DE TABELAS}

TABELA

1 Estimativas dos Coeficientes de Regressão, Coeficientes de Determinação, Coeficientes de Correlação Simples, para as amostras de agricultores das regiões Ribeirão Preto e Sorocaba, Estado de São Paulo, cultura do milho, safra $1975 \ldots \ldots \ldots \ldots \ldots \ldots \ldots \ldots \ldots \ldots \ldots \ldots \ldots \ldots$ 
vii .

\section{LISTA DE FIGURAS}

FI GURA

Pāgina

1 As curvas de oferta da firma moderna e da tradicional não se cruzam, indicando que uma das técnicas é sempre mais vantajosa do que a outra para qualquer volume de produção $\ldots \ldots \ldots \ldots \ldots \ldots \ldots \ldots \ldots \ldots \ldots \ldots \ldots \ldots \ldots \ldots \ldots \ldots \ldots$

2 As curvas de oferta típicas do agricultor tradicional e do moderno se cruzam, indicando que existe um dado volume de produção que iguala a eficiência das duas técnicas e que uma é mais vantajosa quando a produção é inferior a esse ponto, enquanto a outra é a mais vantajosa para quanti dades produzidas acima do ponto de interseção $\ldots \ldots \ldots \ldots \ldots \ldots \ldots \ldots \ldots \ldots \ldots \ldots \ldots \ldots \ldots \ldots \ldots \ldots \ldots \ldots \ldots \ldots \ldots \ldots$

3 As curvas de oferta da firma tradicional e da moderna se cruzam, e a posição da de manda indica uma situação favorāvel a que outras firmas modernizem sua atividade pro

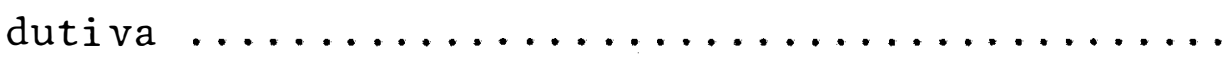


viii.

FI GURA

Página

4 A posição da demanda em relação ao cruzamento das curvas de oferta do produtor tradicional e do moderno indicam uma situação em que a adoção de tecnologia moderna não apresenta van tagem econômica, sendo a técnica tradicional

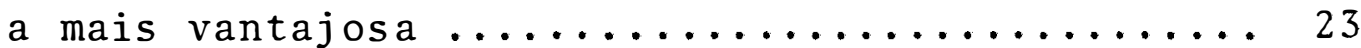

5 Reflexo sobre a firma, do "mecanismo de autocontrole". A interseção entre as curvas de oferta do agricultor "moderno" e do "tradicio nal" coincide com a demanda (preço do produto), indicando que não há estímulo para adoção de inovações tecnológicas, mas também não há prejuízo para os agricultores que as adotaram. A eficiência econômica é semelhante para as

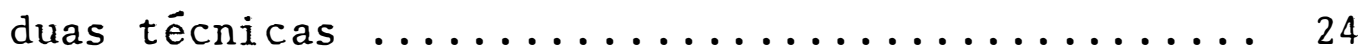

6 Curvas típicas de oferta a curto prazo estima das para amostras de produtores de milho de Sorocaba $\left(\mathrm{Y}_{\mathrm{S}}\right)$ e Ribeirão Preto $\left(\mathrm{Y}_{\mathrm{RP}}\right)$, para 0

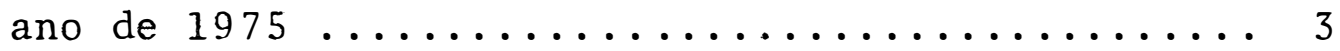

7 Ofertas de milho, a curto prazo, da firma típí ca de Sorocaba $\left(\mathrm{Y}_{\mathrm{S}}\right)$ e uma simulação utilizandose a tecnologia de Ribeirão Preto em uma firma típica de Sorocaba $\left(Y_{S . R P}\right)$, para o ano de $1975 \ldots 36$ 
8 Ofertas de milho, a curto prazo, da firma típica de Ribeirão Preto e uma simulação utilizando-se a mesma tecnologia empregada pela firma de Sorocaba, numa firma típica de Ribeirão Preto, para o ano de $1975 \ldots . . .38$

9 Intervalos de Variação das ofertas de mi1ho, a curto prazo, da firma para as regiões de Ribeirão Preto e Sorocaba, consi derando-se a amplitude de variação dos custos fixos observados nas amostras, no

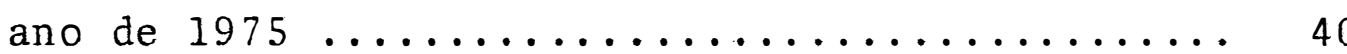


Este estudo tem origem nas discussões sobre a modernização do setor agrícola do Braşil, e se baseia nas funções de oferta como orientadoras da adoção de inovaç̧̧oes tecno lógicas .

O objetivo é identificar grupos homogêneos de estabelecimentos agrícolas situados em estágios tecnológicos diferentes, estimando-se a curva típica de oferta para cada grupo.

0 exemplo estudado foi a produção de milho no Estado de São Paulo, utilizando-se os dados levantados pelo Instituto de Economia Agrícola do Estado de São Paulo na "Pesquisa sobre custo e análise da renda das principais explorações agrícolas para o Estado de São Paulo", no ano de 1975. 
xi .

A comparação é estabelecida entre curvas de oferta da firma típica das regiões produtoras de Ribeirão Preto e Sorocaba, que se situam em níveis diferenciados quanto à modernização do processo de produção do milho.

Os resultados indicam que a tecnologia "moderna" usada na firma de Ribeirão Preto é mais eficiente do ponto de vista privado, do que a técnica "tradicional" empregada pelo agricultor de Sorocaba. Entretanto, o nível mais baixo de efi ciência proporcionado pela técnica "tradicional" não chega a comprometer a lucratividade da exploração, quando a pródução mé dia é inferior a 2.926 sacos por unidade de produção, que é o nível de produção que iguala o custo marginal ao preço. Esses resultados explicam, em parte, a modernização mais intensa ocorrida em Ribeirão Preto onde a produção média é de 4.351 sa cos de milho por estabelecimento agrícola. 
1. INTRODUÇÃO

A agricultura brasileira se caracteriza pela coexistência de técnicas modernas e técnicas tradicionais de cultivo, sendo os padrões médios de produtividade considerados muito baixos em relação aos países desenvolvidos. A elevação da oferta de produtos agrícolas tem sido uma preocupação constante da administração pública nos ültimos anos, sobretudo como arma de combate à inflação e equilíbrio da balança comercial. Nesse sentido, as medidas de política econômica nestes últimos anos tem buscado atingir a esfera da produção através da manipulação dos incentivos fiscais e creditícios, ou mais indireta mente via programas setoriais de investimento em infraestrutura e pesquisa agrícola. 
o volume da produção agrícola poderā sofrer um grande impacto se se conseguir melhorar os padrões de produtividade física atuais, uma vez que o avanço da fronteira agríco la (grande responsável pelo crescimento da produção nos últimos anos) começa a implicar em elevações substanciais nos custos de transporte e de produção, no caso de alguns produtos destinados ao abastecimento alimentar, onde as últimas terras ocupadas são marginais em termos de fertilidade, e frequentemente localizadas em zonas climáticas de alto risco e incertezas. Os incrementos de custos decorrentes de deslocamento das culturas alimentares para äreas de menor aptidão edafo-climáti cas, são sistematicamente repassados para os consumidores em razão do rápido crescimento da demanda interna de alimentos e ao mesmo tempo da necessidade de se aumentar o volume exportado como meio de financiamento das importações, sempre crescentes, e de amortizar a divida externa.

A modernização tecnológica se apresenta como uma necessidade, mais que uma opção, em função da conjuntura desfavorável em que estão mergulhados os países exportadores de produtos agrícolas e importadores de capital e tecnologia, cada vez mais endividados e incapazes de pagar a conta da importação .

Esta modernização pode, no entanto, "colocar em xeque" todo o processo de desenvolvimento econômico, agravando as desigualdades sociais, o desemprego, as migrações internas, a marginalização econômica e social e até mesmo comprometendo 
a necessária expansao do mercado interno, se as inovações tecnológicas preconizadas não forem adequadas às necessidades do país, ou seja, se o processo de modernização não representar solução para alguns problemas estruturais como a fixação do trabalhador à terra, geração de empregos, utilização mais intensiva de fatores de produção com oferta mais elástica, e ao invés, agravar alguns problemas já existentes, ao gerar demanda por fatores mais escassos ou cujo suprimento implique em au mento das importações. 
4 .

\section{REVISÃO BIBLIOGRÁFICA}

PAIVA $(9,10,11,12)$ escreveu que a modernização do setor agrícola provocaria um aumento de produtividade, dando margem a um excedente de produtos não consumível a curto prazo e também de difícil colocação no mercado externo. Esse excedente de oferta sobre a demanda causaria, por sua vez, uma queda no preço dos fatores tradicionais de produção (mão-de-obra e terra), pela própria natureza da modernização que dispensa ou sub-utiliza esses fatores, promovendo uma redução nos seus preços. Em decorrência, a vantagem econômica da moderni zação passaria a decrescer e até mesmo tornar-se negativa, impedindo dessa forma a expansão do processo de difusão por um número cada vez maior de agricultores. 
A esse fenômeno controlador da difusão da tecno logia, PAIVA (10) deu o nome de "mecanismo de autocontrole" que, uma vez que o processo de difusão atingisse um "grau adequado", . colocaria a continuidade do processo na dependência de um cres cimento do setor agrícola a taxas mais elevadas, pois a mão-de-obra deslocada pela modernização das explorações agrícolas teria que ser absorvida pelo setor não-agrícola.

Comentando o modelo de difusão de tecnologia apresentado por Paiva, SCHUH (14) observa que o Autor não deu a devida importância à elevação da renda real decorrente da mo dernização e que teria duas componentes importantes: a) aumen to da renda dos produtores que se modernizaram, devido à maior produtividade proporcionada pela nova técnica; b) aumento da renda real dos consumidores em decorrência da queda no preço dos produtos, provocada pelo aumento da quantidade ofertada, sem que houvesse um correspondente aumento da demanda. Desse modo, sendo a elasticidade-renda dos produtos agrícolas menor que a unidade, uma dada elevação na renda real resultará numa elevação menos que proporcional na parcela destinada ao consumo destes bens. Em consequência, sobraria uma parcela maior de renda para ser aplicada no consumo de bens oriundos do setor não-agrícola, dando margem a novas encomendas às unidades produtoras de bens e serviços, que por sua vez teriam que elevar o nível de emprego, as aquisições de matérias primas, os investimentos, etc. Neste sentido, o aumento da renda real decorrente da modernização do setor agrícola produziria um im- 
pulso dinâmico no setor não-agrícola que poderia anular em par te os efeitos do "mecanismo de autocontrole".

Segundo NICHOLLS'(8), em virtude da resistência natural à modernização, o processo de adoção da nova tecno. logia se dá marginalmente e não por todos os agricultores de uma única vez, de tal modo que considera em grande parte impro cedentes as preocupações de Paiva, acerca de uma produção agrí cola que invariavelmente supere a demanda efetiva.

0 ponto central da teoria da modernização de Paiva, afirma CONTADOR (1), consiste na hipötese de que a exis tência de diferentes níveis tecnológicos de produção, é um fenômeno paralelo e até mesmo fortalecido pelo processo de desen volvimento econômico, em virtude da própria diferenciação entre os agricultores, no que diz respeito a capacitação técnica e econômica, especialização e acesso a fatores de produção específicos.

A característica mais importante do modelo apre sentado por PAIVA (10) e enriquecido pelos comentários de CONTADOR (2) ê a proposição de que as inovações tecnológicas são exógenas ao sistema econômico, importadas dos países desen volvidos que as aprimoraram no intuito de solucionar questões como escassez de alguns fatores de produção ou exigências do mercado consumidor de produtos. O transplante dessa tecnologia para uma outra realidade econômica - a dos países subdesen volvidos como o Brasil - não resulta num perfeito acoplamento entre os problemas existentes e as soluções tecnológicas encon 
tradas. Desse modo, a difusão de técnicas e insumos modernos, nem sempre mais rentáveis que os processos tradicionais de cul tivo, é forçada por uma política de incentivos e subsídios des tinados a alterar os custos relativos ao nível do agricultor, produzindo uma vantagem "artificial" para adoção de tecnologia moderna.

As inovações tecnológicas podem ser de vários tipos: Químicas, que acarretam um aumento substancial nos gas tos variáveis; Mecânicas, ạue resultam numa elevação dos gastos fixos por parte de quem as adota; Biológicas, que representam uma alteração pequena nos custos mas podem produzir ganhos significativos de produtividade. Existe ainda um outro tipo de inovações, denominado por PAIVA (10) de "não onerosas", que praticamente não acarretam incrementos no custo de produção, pois se referem a alterações no manejo, tais como, rotação de culturas, épocas de plantio, espaçamento, densidade, consorciação, etc.

Esse ūltimo grupo de inovações não è considerado por PAIVA (10) de muita importância para os países subdesen volvidos, pois concorda com SCHULTZ(15) em que os agricultores tradicionais são eficientes no"manejo das técnicas tradicionais, e que é praticamente impossível obter maiores rendimentos através tão somente do controle dessas variáveis.

As inovações tecnológicas dos tipos "biológicas" e "químicas" dificilmente podem ser importadas dos países de origem e aplicadas diretamente sem um programa de investimento 
maciço em pesquisa e experimentação agropecuária, pois respondem a condições específicas de clima, solo, oferta de fatores e mercado para o produto.

Assim, o processo de modernização do setor agrí cola nos países importadores de tecnologia tende a seguir o caminho da mecanização, cuja adaptação é rảpida e eficiente e depende unicamente da topografia e morfologia dos solos e de mecanismos financeiros que abrandem os custos da sua utilização. A mecanização das operações de cultivo eleva a produtividade marginal do fator trabalho, cuja oferta é elástica no setor primário de países subdesenvolvidos, e exige grandes inversōes de capital, cuja oferta é inelástica (dadas as limitações da poupança interna), resultando onerosa a sua adoção pelos agricultores que em contrapartida não conseguem um incremento correspondente de produção por hectare.

Para que haja modernização é necessārio, segundo PAIVA (11), que a técnica moderna seja econômicamente mais vantajosa do que a técnica tradicional.

Um modelo diferente e apoiado em algumas evidên cias históricas foi o apresentado por HAYAMY e RUTTAN (7), para explicar a modernização da agricultura. Segundo os autores, o processo de geração de tecnologia se desenvolve tendo em vista a constelação de recursos em cada país. Os países com oferta inelástica do fator mão-de-obra, tendem a desenvolver uma tecnologia voltada para a utilização em larga escala 
do fator terra, elevando a produtividade do fator trabalho, enquanto os países com oferta.inelástica de terras agricultáveis tenderiam a desenvolver uma tecnologia poupadora de terra, elevando a produção por unidade da ärea. Se as inovações tec nológicas estivessem a cargo de empresas privadas, a sua orien tação seria no sentido da maximização do lucro, com elevação da produtividade marginal do fator mais dispendioso, e no caso em que as inovações tecnológicas estivessem sendo produzidas por entidades oficiais, a pesquisa seria orientada no sentido de uma maximização do bem estar social, por intermédio de um uso mais racional dos fatores de maior escassez relativa. Esta hipótese é aceita por PASTORE et alii. (13) quando analisam, em relação ao caso brasileiro, que não se pode falar propriamente em escassez do fator terra ou escassez de mão-de-obra de forma generalizada, contudo, devido aos estímulos governamentais voltados para a utilização de Capital, é de se esperar que a modernização tenha seguido um padrão de tecnologia do tipo "capital intensive", a exemplo do modelo norte-americano.

Como a modernização através da mecanização numa situação de oferta elástica de mão-de-obra implica um desemprego generalizado, Paiva tem razão, quando condiciona a difusão das inovações tecnológicas ao crescimento do setor não-agrícola. E preciso analisar, entretanto, dizem os mesmos autores, quais as fontes geradoras dessas inovações. As inovações biológico-químicas não necessariamente poupadoras de mão-de-obra, podem derivar do crescimento do setor industrial 
e urbano do país, absorvendo portanto, um contingente de mão- de-obra cada vez maior, o que induziria por sua vez o progres so tecnológico no sentido da mecanização, sem que se colocasse o problema do desemprego. E finalizam, afirmando que a análi se realizada por Paiva contém as hipóteses cruciais sobre a inovação tecnológica, as quais não podem ser questionadas do ponto de vista teórico, por falta de evidências empíricas não existentes no momento.

CONTADOR (3) procurando identificar os determinantes da adoção e mudança tecnológica na agricultura brasilei ra, utilizou dados obtidos por Paiva em estabelecimentos rurais de Ceará, Pernambuco, Espírito Santo, Minas Gerais, São Paulo, Santa Catarina e Rio Frande do Sul, comparando os resultados de dois levantamentos em períodos distintos, 1962/64 e 1969/70. A construção de um índice de tecnologia foi o critério adotado para a identificação do estágio estático de tecnologia. No índice geral de tecnologia estavam agregados com pesos diferen tes, os distintos tipos de inovação tecnológica adotados no estabelecimento, sendo o somatório dos pesos igual à unidade. A representação gráfica de todos os estabelecimentos através do índice geral de tecnologia, dentro de cada Estado, demonstrou um enorme grau de dispersão entre o nível tecnológico de produção dos estabelecimentos rurais. Em alguns Estados a modernização foi mais intensa nos estabecimentos que se encontravam nos estágios mais baixos de tecnologia (Ceará e Espírito Santo), enquanto em outros, os avanços mais sensiveis ocor- 
reram num estágio "semimoderno" (Santa Catarina, Rio Grande do Sul e Pernambuco) ou num estágio avançado de adoção tecnológica (São Paulo) .

Concluindo, CONTADOR (3) aponta a taxa média de retorno, a mudança no acesso ao crédito e a mudança na produtí vidade marginal do solo como os fatores responsáveis pelo avan ço tecnológico nos estabelecimentos rurais. A atividade pre dominante e o nível educacional do administrador foram signifí cantes em poucos casos, enquanto que o tamanho da propriedade e condição do responsável (proprietário, parceiro, arrendatário) não foram significantes em nenhum caso. A dispersão de técnicas entre os estabelecimentos é explicável pela escala, pela educação e condição do responsável, pela atividade, pela taxa de retorno do estabelecimento, pelo acesso ao crédito, pe la qualidade do solo e distância dos centros urbanos. Verificou que o dinamismo do processo de adoção da nova tecnologia é diferente para cada Estado. Os Estados do Nordeste apresen taram uma adoção mais lenta do que os Estados do Sul, o que im plica numa tendência à perpetuação das disparidades regionais, se forem mantidas as mesmas condições existentes nos anos 1962 a 1970, quando a política econômica estimulou a modernização do setor, via alterações favoráveis nos preços relativos dos fatores modernos. 
3. OBJETIVOS

O objetivo principal do trabalho é identificar grupos homogêneos de estabelecimentos agrícolas situados em es tágios tecnológicos diferentes, estimando-se a curva típica de oferta da firma para cada grupo.

$$
\text { A título de simplificação serão considerados }
$$

apenas dois grupos, do mesmo modo como PAIVA (10) simplificou sua análise sobre a modernização da agricultura a nível de me cado.

A análise das curvas de oferta de cada firma tí pica possibilitará identificar as implicações em termos de resposta a preços e de racionalidade econômica, decorrentes da existência de diferentes padrōes tecnológicos num mesmo ramo de negócio. 
13.

4. MATERIAL E MÉTODO

O processo de modernização do setor agrícola se desenvolve em meio a uma mudança contínua nos preços relativos dos fatores de produção. Não obstante, um componente importante do processo de difusão tecnológica é a condição favorável de tais preços, ou seja, a substituição de técnicas tradicionais por tecnologia moderna é motivada pela possibilidade de ampliação dos benefícios internos que esta enseja.

0 modelo de Paiva sugere que a modernização da agricultura pode gerar uma ineficiente alocação de recursos a nível macroeconômico, se o "grau privado adequado" de modernização for ultrapassado, quer dizer, se o processo de adoção de inovações tecnológicas prosseguir além dos limites impostos pe 
10 "mecanismo de autocontrole" via preços relativos. Nesse caso, o estímulo à adoção de inovações pelo setor privado da produção agrícola é estabelecido através de uma política econô mica que transfere para a sociedade uma parte do custo privado da inovação. Esse aspecto da diferença entre custo privado e custo social e benefício privado e benefício social da moderni zação tecnológica não será abordado nesse trabalho, que procura enfatizar os aspectos microeconômicos da modernização. En tretanto, a sua transposição nara o nível macro e a eventual inserção do conceito de "custo social" poderão ser invocados como explicação de algumas imperfeições que não encontram sufi ciente explicação na teoria da firma.

A ação do "mecanismo de autocontrole" se reflete a nível de estabelecimento agrícola na vantagem ou desvanta gem da técnica moderna sobre a tradicional, e enseja a existên cia de diversos grupos de unidades produtoras, operando cada um deles num diferente estágio de modernização do processo pro dutivo.

A identificação na prática de uma situação desse tipo, onde se pode caracterizar as curvas típicas de oferta associadas a cada grupo homogêneo de estabelecimentos situados num patamar tecnológico comum, é mais uma contribuição para a discussão em torno da modernização da base produtiva do setor agrícola.

Serão utilizados os dados obtidos junto a agricultores de Ribeirão Preto e Sorocaba, Estado de São Paulo, 
pelo Instituto de Economia Agrícola, e que serviram de base pa ra determinação do custo de produção e custo operacional para o milho no ano de 1975.

$\bar{A}$ primeira vista as duas regiões produtoras, Ri beirão Preto e Sorocaba, apresentam diferenças substantivas en tre si quanto à tecnologia empregada na produção de milho e ao mesmo tempo uma certa homogeneidade interna de tecnologia enquanto zonas produtoras de milho.

Os resultados preliminares da "Pesquisa sobre custo e análise da renda das principais explorações agrícolas para o Estado de São Paulo" do I.E.A. em anexo, indicam que em Ribeirão Preto, o custo fixo tem uma participação maior na for mação do custo unitário do que em Sorocaba (41 contra 36\%).

Segundo essa mesma pesquisa, foram mais signif $\underline{i}$ cativos em Ribeirão Preto do que em Sorocaba, os itens relativos a juros sobre o capital fixo (29 contra $26 \%$ ), depreciação $(8,2$ contra $6,5 \%)$, reparos de máquinas e equipamentos $(3,6$ con tra $1,4 \%$ ), adubos e corretivos (29,6 contra $27,6 \%$ ) e juros sobre o capital circulante $(5,9$ contra $3,9 \%)$, na formação do cus to unitärio, indicando um nível mais elevado dos investimentos e de utilização de fatores "modernos" na exploração agrícó เa.

Em Sorocaba, por sua vez, na comparação das estruturas do custo unitário em relação a Ribeirão Preto, foram mais expressivos o custo da mão-de-obra $(17,5$ contra $8,33 \%$ e 
alimentação de animais de trabalho $(0,52$ contra $0,07 \%)$.

A produção média de milho por hectare no ano de 1975 foi 14\% superior em Ribeirão Preto onde foram colhidos em média $2.494 \mathrm{~kg}$ por hectare, contra $2.179 \mathrm{~kg} / \mathrm{ha}$ em Sorocaba ${ }^{1}$, o que reforça mais uma vez as diferenças existentes entre os padrões médios ou predominantes de tecnologia, do produtor de mi 1ho de Ribeirão Preto para o de Sorocaba.

o pressuposto adotado serā então de dois padrões tecnológicos que se identificam com as duas regiões.

Cada uma das regiões de produção será representada por uma amostra de produtores de milho. Os agricultores de Ribeirão Preto, que aparentemente jă alcançaram um nível mais elevado de adoção de inovações tecnológicas, serão caracterizados como "agricultores modernos", enquanto os de Sorocaba, num nível de tecnologia um pouco mais baixo, serão chamados de "agricultores tradicionais". Não se emprestou o devido ri gor aos conceitos "moderno" e "tradicional" que são usados como força de expressão. O mais correto seria empregar expressões como: "modernos" e "mais modernos" ou "muito modernos" e "muitíssimo modernos", dadas as diferenças tecnológicas existentes entre estes agricultores e outros localizados, por exem plo, em Irecê e Ribeira do Pombal na Bahia, onde a condição de

\footnotetext{
1 A produtividade média do milho nas duas regiões foi calculada com base nos dados do Censo Agropecuário de São Paulo, 1975 da FIBGE (5).
} 
agricultores "tradicionais" é incontestável.

4.1. Hipóteses sobre as curvas de oferta

A comparação gráfica entre as curvas de oferta dos produtores "tradicionais" e "modernos" pode resultar nas seguintes situações:

a) as curvas de oferta não se cruzam, indicando que uma das duas técnicas empregadas é a mais rentável qualquer que seja o volume de produção. PAIVA (10) cita o exemplo da cultura da mandioca onde, no julgamento dele, a técnica tradi :ional é sempre mais rentável do que a técnica moderna, e cita rambém o caso da fruticultura de clima temperado, no cinturão verde de São Paulo, onde a técnica moderna é sempre mais econô ca do que a técnica tradicional (Fig. 1).

b) as curvas de oferta se cruzam, mostrando que para uma determinada quantidade produzida, ambas as técnicas, "tradicional" e "moderna", apresentam a mesma economicidade e que para uma produção inferior à representada nesse ponto uma delas é a mais rentável enquanto para uma produção superior a es se ponto a outra técnica é a mais rentável (Fig. 2).

Ao se introduzir na representação gráfica a posição da curva de demanda (que para cada produtor individual mente é infinitamente elástica, representada pelo preço do pro 
18.

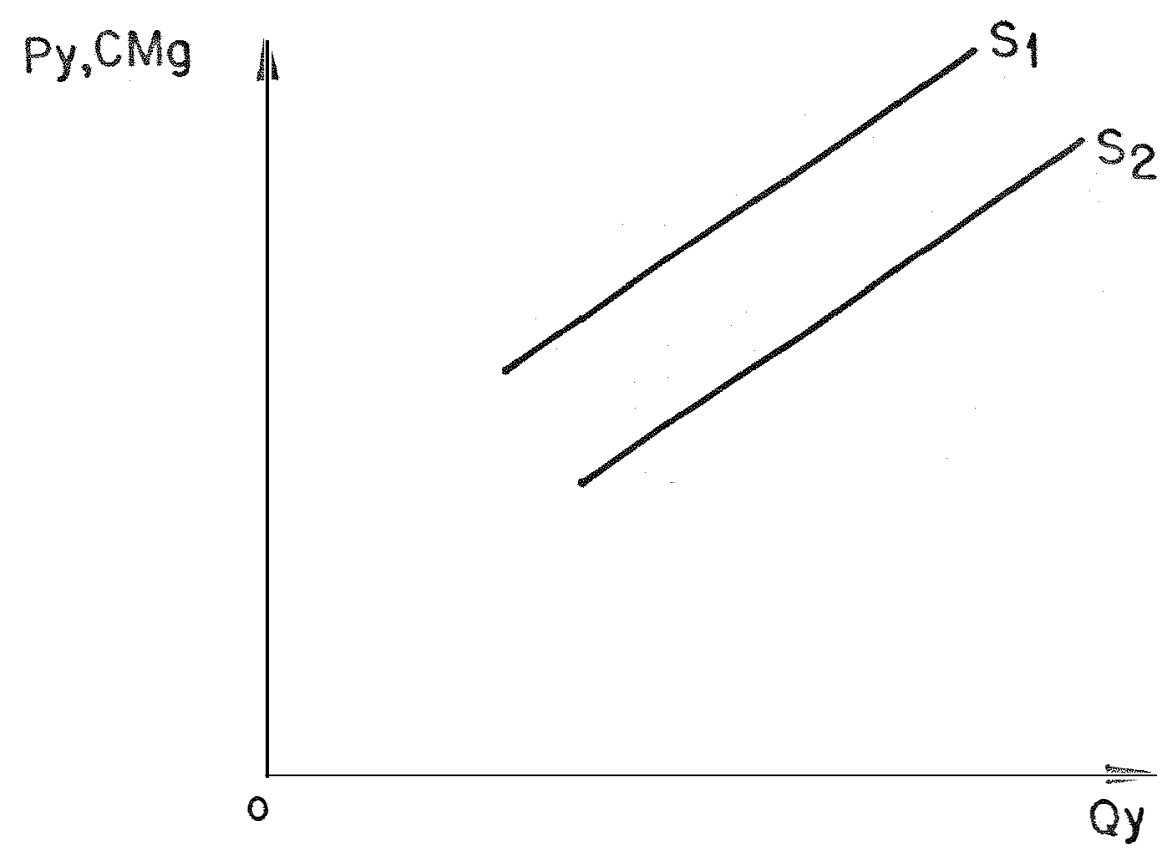

Fig. 1. As curvas de oferta da firma moderna e da tradicional não se cruzam, indicandó que uma das técnicas é sempre mais vantajosa do que a outra para qualquer volume de produção. 


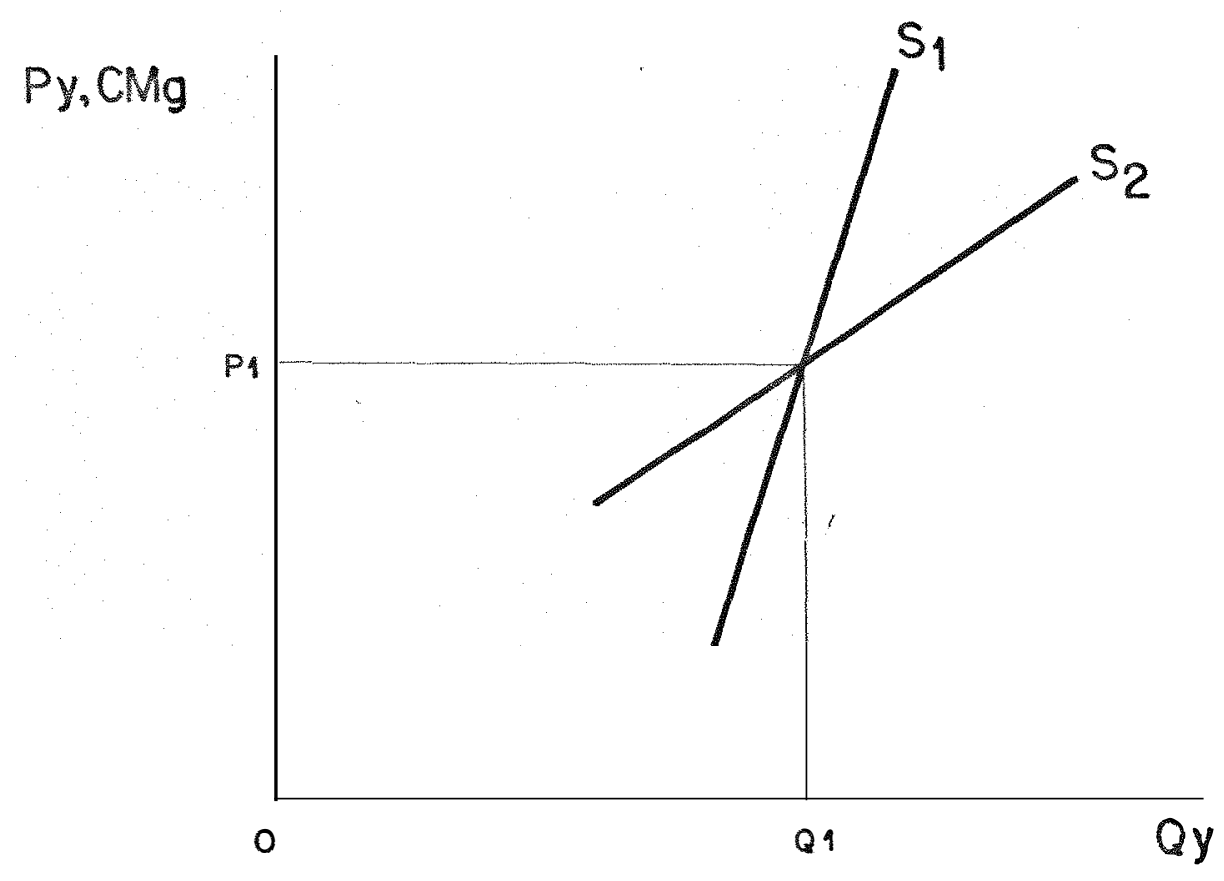

Fig. 2. As curvas de oferta típicas do agricultor tradicional e do moderno se cruzam, indicando que existe um dado volume de produção que iguala a eficiência das duas técnicas e que úma é mais vantajosa quando a produção é inferior a esse ponto, enquanto a outra éa mais vantajosa para quantidades produzidas acima do ponto de interseção. 
duto) é importante verificar se o cruzamento entre as duas cur vas de oferta se processa acima ou abaixo da curva de demanda.

Pressupondo-se a curva de oferta dos agricultores tradicionais menos elástica em relação ao preço do que a curva de oferta dos agricultores modernos, devido à dificuldade de se expandir a produção dentro da técnica tradicional, o ponto de interseção entre as duas curvas de oferta representa o limite máximo de um campo onde está definida a superioridade da técnica tradicional sobre a técnica moderna. Acima desse ponto, ou seja, para volumes crescentes de produção, o quadro se inverte, com a técnica moderna tornando-se economicamente mais vantajosa do que a técnica tradicional.

Se a adoção de inovações tecnológicas somente se processa em condições de vantagem econômica (PAIVAop. cit.) é necessārio para que haja "dualismo econômico" (existência de dois tipos de agricultores produzindo economicamente com níveis distintos de tecnologia) que a curva de demanda esteja acima do ponto de interseção entre as curvas de oferta dos agricultores tradicionais e modernos. O preço será então, um estímulo à modernização do processo produtivo e à expansão da oferta. Embora as condições estejam favoráveis à produção com tecnologia moderna, os agricultores tradicionais permanece rão economicamente produtivos, mas numa escala bem reduzida de operação. Esta situação é ilustrada com a Fig. 3, onde ST é a oferta dos agricultores tradicionais, SM é a oferta dos agri cultores modernos e PM é a demanda (infinitamente elástica). 
QT serā a quantidade de equilíbrio dos agricultores tradicionais e QM a quantidade de equilíbrio dos agricultores modernos. o benefício líquido proporcionado pela técnica moderna será re presentado por (a) no ponto de equilíbrio da técnica tradicional. O estímulo à modernização estará definido na ärea do triângulo (b) entre $\mathrm{QT}^{\mathrm{T}}$ e $\mathrm{M} M$ e a tendência natural é de moder nização de todos os produtores que iriam deslocando a sua

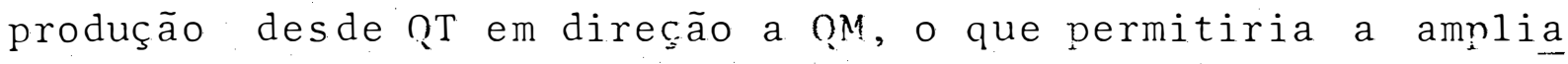
ção de sua receita total representada pela área (c). Entretan to, a expansão do processo de difusão fatalmente modificaria, segundo Paiva, o nível de preços forçando para baixo a reta PM, o que traria como consequência a eliminação gradativa do estímulo à modernização associado à técnica moderna (triângulo b), e o estreitamento, do benefício desta para aqueles agricultores que já a tivessem adotado (a).

Outro caso seria o representado pela Fig. 4, on de o cruzamento entre as curvas de oferta dos agricultores tra dicionais e modernos se dá acima da curva de demanda, não havendo nenhum estímulo à modernização. A técnica tradicional seria a única economicamente viável para o aumento da produção, e a sua vantagem sobre a técnica moderna, definida pela ärea (d) . Nessa situação a modernização tecnológica só seria posSivel com uma política de elevação de preços agrícolas (PM) e alteração nos preços relativos dos fatores de produção associa das às curvas de oferta com tecnologia "tradicional" e "moderna". 


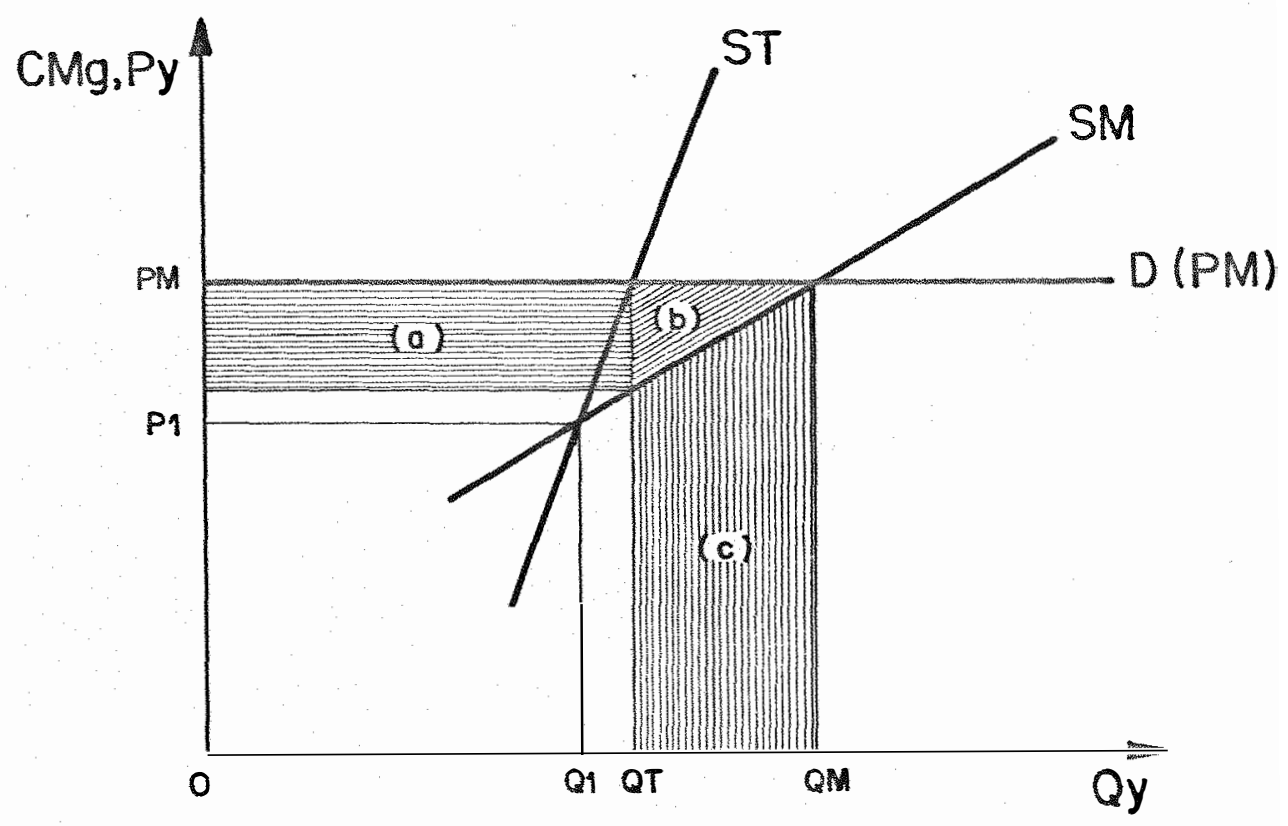

Fig. 3. As curvas de oferta da firma tradicional e da moderna se cruzam, e a posição da demanda indica uma situação favorävel a que outras firmas modernizem sua atividade produtiva. 


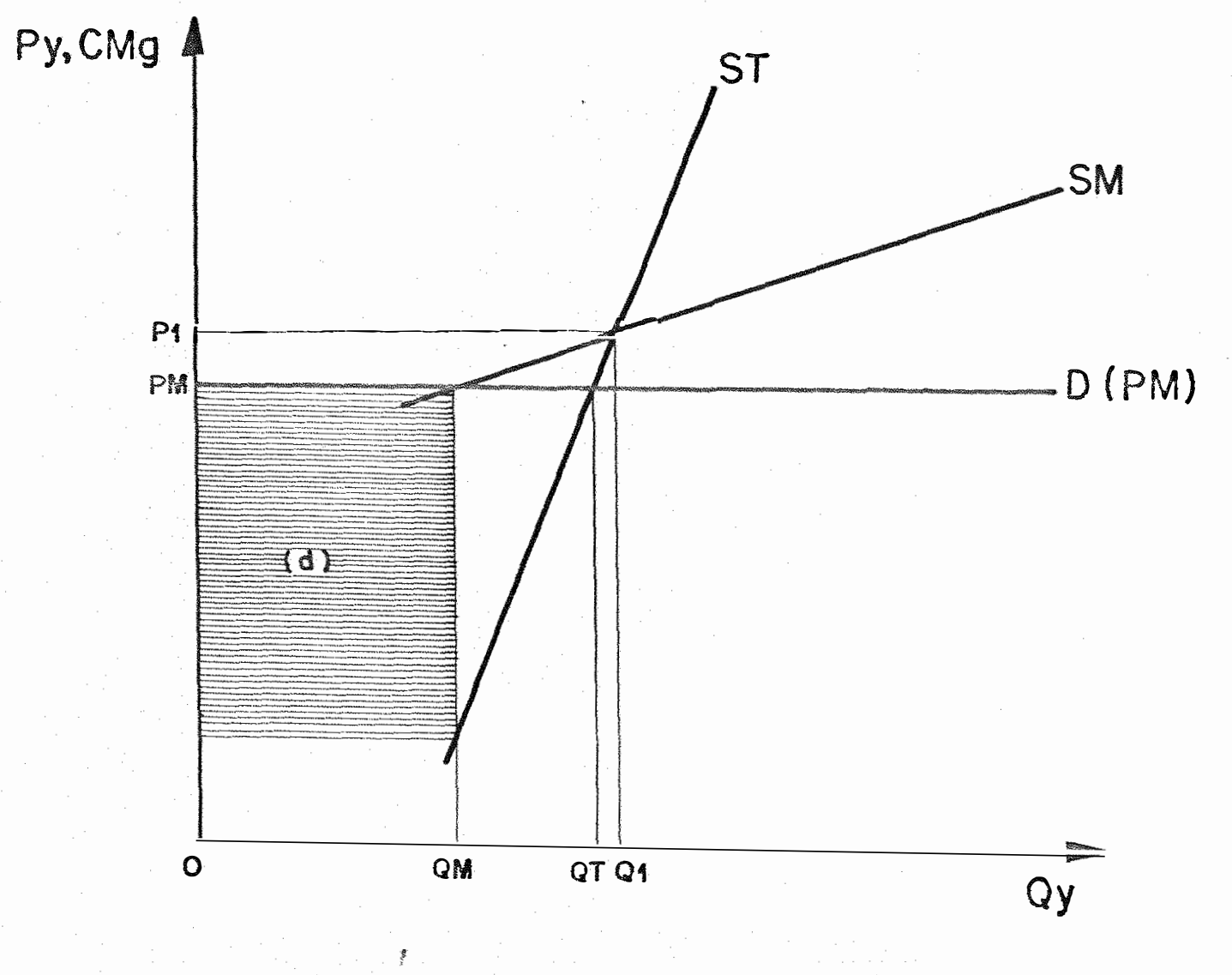

Fig. 4. A posição da demanda em relação ao cruzamento das curvas de oferta do produtor tradicional e do moderno indicam uma situação em que a adoção de tecnologia moderna não apresenta vantagem econômi ca, sendo a técnica tradicional a mais vantajosa. 
o grau adequado de modernização, determinado pe la ação do mecanismo de "autocontrole", seria uma situação semelhante à ilustrada na Fig. 5, onde o cruzamento entre as duas curvas de oferta coincide com a curva de demanda ou está muito próximo dela.

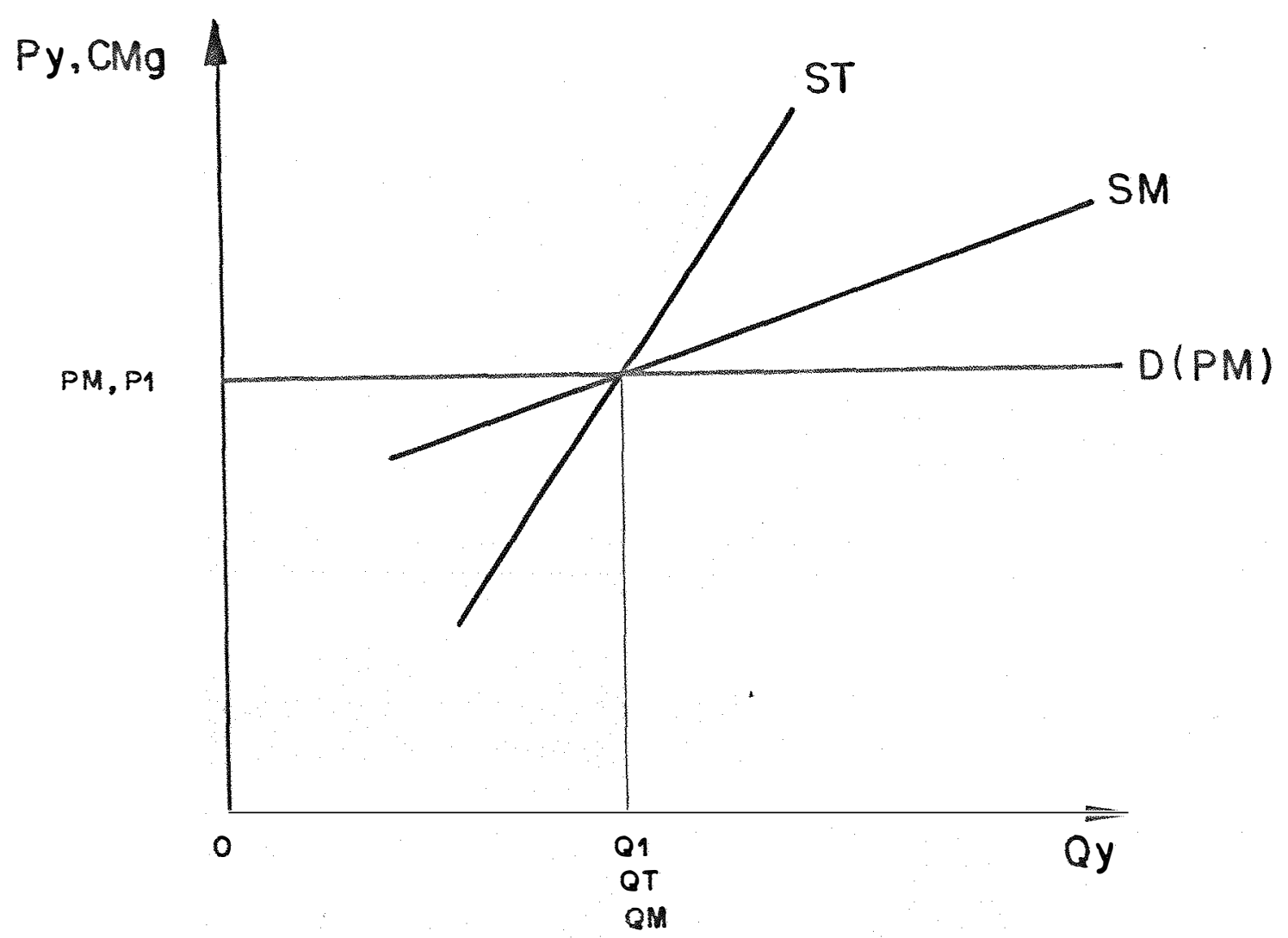

Fig. 5. Reflexo sobre a firma, do "mecanismo de autocontrole". A interseção entre as curvas de oferta do agricultor "moderno" e do "tradicional" coincide com a demanda (preço do produto), indicando que não há estímulo para adoção de inovações tecnológicas, mas também não há prejuízo para os agricultores que as adotaram. A eficiência econômica é semelhante para as duas técnicas . 
4.2. Método de estimação

A função de oferta do estabelecimento pode ser derivada da relação matemática

$$
Y=f\left(X_{1}, X_{2}\right)
$$

onde $\mathrm{Y}$ é a produção física por estabelecimento, $\mathrm{X}_{1}$ é o custo variāvel e $x_{2}$ é o custo fixo.

A relação $Y=f\left(X_{1}, X_{2}\right)$ seră estimada segundo uma equação do tipo COBB - DOUGLAS, que apresenta semelhanças com a forma algébrica da relação entre Produção e Custo, uma vez que os modelos cúbicos e quadráticos ajustados anteriormen te apresentaram problemas de especificação.

$$
\mathrm{Y}=\mathrm{ax}_{1}^{\mathrm{b}_{1}} \mathrm{x}_{2}^{\mathrm{b}_{2}}
$$

que por transformação logarítmica assume a seguinte forma:

$$
\log Y=\log a+b_{1} \log X_{1}+b_{2} \log x_{2}
$$

onde todos os parâmetros são maiores que zero e a soma dos mes mos menor ou igual à unidade.

Da COBB - DOUGLAS em sua forma natural a função de custo variável é determinada em:

$$
X_{I}=\left(\frac{Y}{a x_{2}{ }^{b_{2}}}\right)^{\frac{1}{b_{1}}}
$$


o custo marginal é dado pela derivação parcial do custo variável, considerando-se o custo fixo constante no curto prazo. Igualando-se a derivada ao preço do produto $\left(\mathrm{P}_{\mathrm{y}}\right)$ obtém-se a equação da oferta típica da firma para cada amostra

$$
\mathrm{CM}=\frac{\mathrm{d} \mathrm{X}_{1}}{\mathrm{~d} \mathrm{Y}}=\left(\frac{\mathrm{I}}{\mathrm{a} \mathrm{X}_{2}{ }^{\mathrm{b}}}\right)^{-\frac{1}{\mathrm{~b}_{1}}} \cdot \frac{1}{\mathrm{~b}_{1}} \cdot \mathrm{Y}^{\frac{1-\mathrm{b}_{1}}{\mathrm{~b}_{1}}}=\mathrm{P}_{\mathrm{y}}
$$

Explicitando-se a equação em $Y$ (quantidade ofer t.ada) :

$$
Y=P_{y}^{\frac{b_{1}}{1-b_{1}}} \cdot b_{1}^{\frac{b_{1}}{1-b_{1}}} \cdot\left(a x_{2}^{b_{2}}\right)^{\frac{1}{1-b_{1}}}
$$

que e a função de oferta a ser estimada para cada agricultor típico (tradicional ou moderno) nas zonas de produção respectị vas de Sorocaba e Ribeirão Preto.

A elasticidade-preço da oferta será para cada equação igual a

$$
E=\frac{b_{1}}{1-b_{1}}
$$

Os parâmetros da função de oferta serão conhecị dos estimando-se a função

$$
\log Y=\log a+b_{1} \log X_{1}+b_{2} \log x_{2}
$$

através do método dos mínimos quadrados ordinários. 
o custo fixo serâ uma constante igual à média geométrica dos custos fixos observados em cada um dos conjuntos homogêneos (Ribeirão Preto e Sorocaba, respectivamente) ${ }^{2}$.

\subsection{Descrição das variáveis ${ }^{3}$}

Custo Variável $\left(x_{1}\right)$

o custo variável é medido em cruzeiros e se refere aos gastos com mão-de-obra, reparos de máquinas e equipamentos de tração animal e tração mecânica, alimentação de an mais de trabalho, adubos e corretivos, defensivos, sementes, embalagem, serviços de empreita, combustíveis e lubrificantes, Funrural e juros sobre o capital circulante.

\section{Cus to Fixo $\left(\mathrm{x}_{2}\right)$}

$\vec{E}$ medido em cruzeiros e proporcional à participação da área cultivada com milho sobre a área total disponí-

2

O método de estimação está descrito com detalhes em GRAÇA et alii (6), quando ajustam funções de oferta de soja no curto prazo para vários municípios do Estado do Paraná.

3

o custo variável e o custo fixo foram determinados através de um programa para Computadores IBM 1130, desenvolvido no Departamento de Matemática da ESALQ para a "pesquisa sobre custo e análise da renda das principais explorações agrícolas para o Estado de São Paulo", do Instituto de Economia Agrícola da Secretaria da Agricultura de São Paulo. 
vel do estabelecimento ${ }^{4}$. O custo fixo se refere a juros sobre o capital fixo, valor do arrendamento, depreciação de benfeitorias e instalações, máquinas e equipamentos de tração animal e tração mecânica, impostos e taxas, sindicato rural, licenciamento de veículos, taxa de conservação de estradas, des pesas gerais com material de escritório, telefone, luz e INCRA.

\section{Produção Física (Y)}

$\bar{E}$ medida em sacos de $60 \mathrm{~kg}$, e representa a quantidade total de milho produzida no estabelecimento no ano de 1975 .

4

Foi considerada como área total disponível no estabelecimen to, a soma das áreas próprias com as āreas arrendadas. 
5. RESULTADOS

As funções de produção ajustadas para as amostras de produtores de milho em Sorocaba e Ribeirão Preto apresentaram os seguintes resultados.

Tabela 1. Estimativas dos Coeficientes de Regressão, Coeficien tes de Determinação, Coeficientes de Correlação Sim ples, para as amostras de agricultores das regiões Ribeirão Preto e Sorocaba, Estado de São Paulo, cul tura do milho, safra 1975 .

\begin{tabular}{lcccccccccc}
\hline Amostra & $\mathrm{N}$ & $\mathrm{a}$ & $\mathrm{b}_{1}$ & $\mathrm{~b}_{2}$ & $\mathrm{r}_{12}$ & $\mathrm{R}^{2}$ & $\mathrm{~F}$ & $\mathrm{t}_{1}$ & $t_{2}$ \\
\hline R. Preto & 59 & 0,2496 & 0,7105 & 0,2854 & 0,8442 & 0,8053 & 115,80 & 5,928 & 2,509 \\
Sorocaba & 46 & 0,7082 & 0,5066 & 0,2712 & 0,7100 & 0,8086 & 90,84 & 6,414 & 3,796 \\
\hline
\end{tabular}

NOTA: $\quad \mathrm{N}=\mathrm{n}$ : de observaçōes; $a$ =intercepto; $\mathrm{b}_{1}$ e $\mathrm{b}_{2}=$ coeficiente de regressão de $x_{1}$ e $x_{2} ; r_{12}=$ coef. de correlação simples entre $x_{1}$ e $x_{2}$; $\mathrm{R}^{2}=\operatorname{coef}$. de determinação e $F, t_{1}$ e $t_{2}=$ testes estatísticos. 
O teste " $t$ " mostrou-se significativo a $1 \%$ para todos os coeficientes estimados, exceto para b 2 na função de produção ajustada para a amostra de produtores da região de Ribeirão Preto, que mostrou-se significativo a $2 \%$.

0 teste "F" mostrou-se significativo a $1 \%$ para as duas regressões estimadas.

Os Coeficientes de Determinação de 0,8053 e 0,8086, respectivamente para as regressões de Ribeirão Preto e Sorocaba, indicam que as equações ajustadas são capazes de oferecer uma boa explicação das variações na variável dependen te (produção física de milho em sacas de $60 \mathrm{~kg}$ ).

As variäveis independentes $\left(X_{1}\right.$ e $x_{2}$, custos va riāveis e fixos respectivamente) apresentaram entre si uma correlação muito estreita, o que pode resultar numa distorção nas estimativas dos coeficientes de regressão.

As funções de oferta da firma estimadas para as duas amostras de agricultores são apresentadas a seguir. Estas funções são derivadas das relações algébricas entre custos e produção cujos parâmetros se encontram na Tabela 1 .

Agricultores "tradicionais" (Região de Sorocaba)

$$
\begin{gathered}
\mathrm{Y}_{\mathrm{S}}=\mathrm{P}_{\mathrm{y}}^{1,0268} \cdot 0,5066^{1,0268} \cdot 0,7082^{2,0268} \cdot 18607,011^{0,5497} \\
\text { donde, } \mathrm{Y}_{\mathrm{S}}=54,9654 \cdot \mathrm{P}_{\mathrm{y}}^{1,0268}
\end{gathered}
$$


Agricultores "modernos" (Região de Ribeirão Preto)

$$
Y_{R P}=P_{y}^{2,4542} \cdot 0,7105^{2,4542} \cdot 0,2496^{3,4542} \cdot 44629,86^{0,9852}
$$$$
\text { donde, } \quad Y_{R P}=137,1240 \cdot P_{y}^{2,4542}
$$

o valor do custo fixo $\left(x_{2}\right)$ foi considerado como não variando no curto prazo, sendo o seu valor fixado numa cons tante igual à média geométrica dos custos fixos observados em cada amostra.

A média geométrica dos custos fixos observados em Ribeirão Preto foi de $\operatorname{Cr} \$ 44.929,86$ por estabelecimento agrí cola, enquanto em Sorocaba a mesma medida foi $\operatorname{Cr} \$ 18.607,01$.

As elasticidades-preço da oferta obtidas para as equações de oferta típica das amostras de produtores de milho em Ribeirão Preto e Sorocaba foram 2,4542 e 1,0268 respectivamente. As elasticidades da oferta demonstram que um produtor típico da região de Ribeirão Preto possui uma curva de oferta bem mais elástica do que a de um produtor típico da região de Sorocaba, não obstante estes também possuam uma oferta elástica, pois podem elevar a sua produção em $10,27 \%$ se o preço for elevado em 10\%. Em Ribeirão Preto a resposta é bem mais significativa, podendo a oferta alcançar um incremento de até $24,54 \%$ se o preço aumentar de $10 \%$.

A representação gráfica das funções de oferta estimadas para os dois grupos de agricultores (Fig. 6), demons 
tra que o custo marginal do produtor típico de milho em Ribeirão Preto cresce muito lentamente, enquanto para o produtor tí pico da região de Sorocaba esse crescimento é vertiginoso, a incrementos positivos da quantidade produzida, devido às diferenças substanciais entre as elasticidades de oferta.

As duas curvas de oferta não se cruzam, enquanto curvas de oferta, embora as expressões algébricas que repre sentam as curvas de oferta tenham um ponto em comum $\left(\mathrm{P}_{\mathrm{y}}=\right.$ $=0,5270 ; y=28,4737)$ mas sem qualquer significado econômico. Isto estaria indicando que, uma das duas tecnologias é sempre mais vantajosa, qualquer que seja o volume produzido. O custo marginal de produção com a tecnologia empregada em Ribeirão Preto é sempre inferior ao custo marginal da produção de milho em Sorocaba.

0 custo unitário de produção foi de $\operatorname{Cr} \$ 48,93$ e Cr\$44,14, respectivamente para os produtores das regiões de Sorocaba e Ribeirão Preto. Essa ligeira vantagem no custo uni tário é decorrente da mudança na base produtiva, que gera ganhos de produtividade e custos decrescentes com escala mais al ta de produção. Com a tecnologia empregada em Sorocaba a pro dução média é de 1.701 sacos de milho por estabelecimento, poden do chegar a um máximo econômico de 2.926 sacos quando o custo marginal se iguala ao preço do mercado. O preço médio de mer cado recebido em 1975 pelos produtores de milho do Estado de São Paulo e que foi utilizado na pesquisa, segundo a FGV (4) é de $\operatorname{Cr} \$ 48,00$ por saco de $60 \mathrm{~kg}$. 


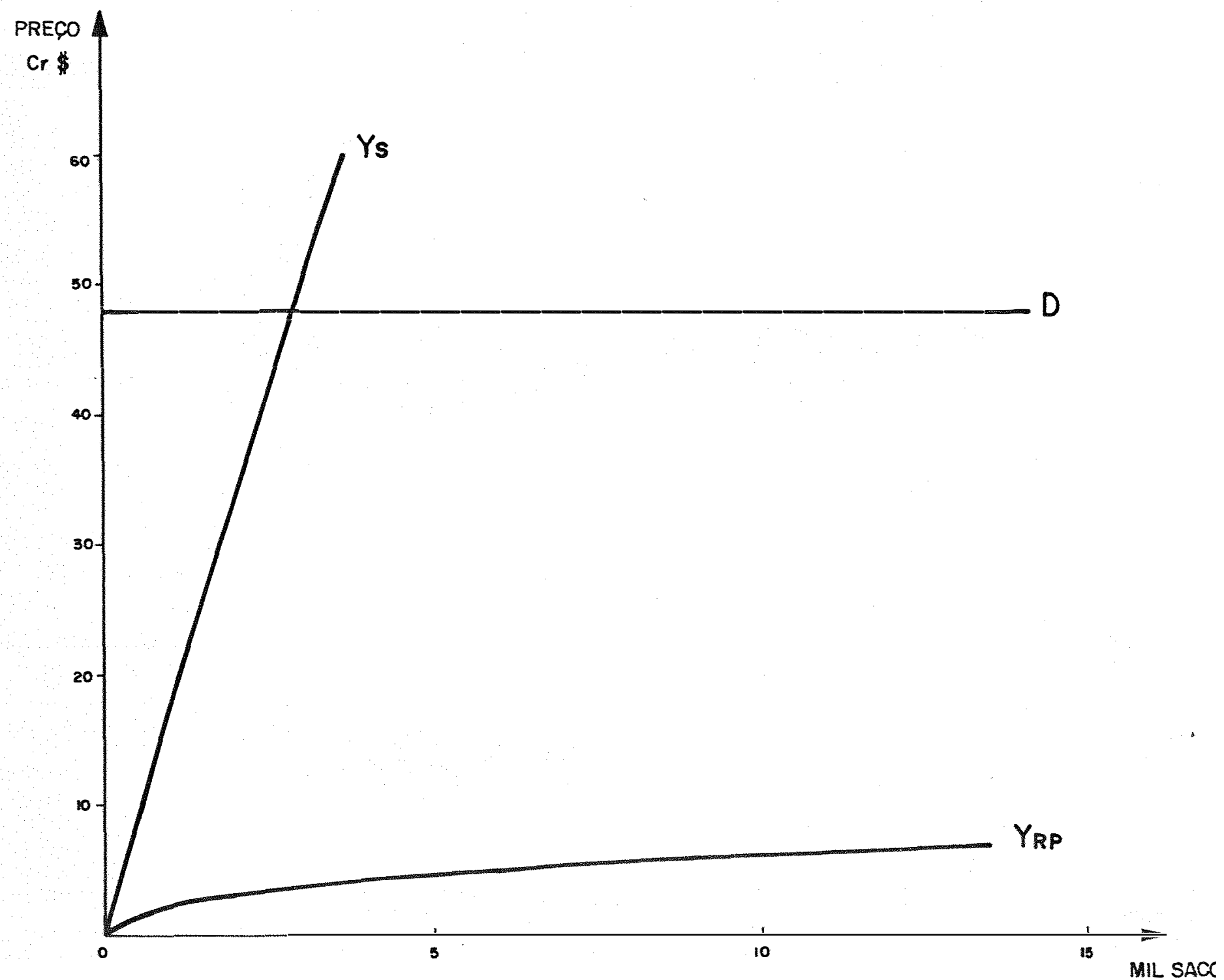

Fig. 6. Curvas típicas de oferta a curto prazo estimadas para amostras de produtores de milho de Sorocaba $\left(\mathrm{Y}_{\mathrm{S}}\right)$ e Ribeirão Preto $\left(\mathrm{Y}_{\mathrm{RP}}\right)$, para o ano de 1975 . 
Os agricultores de Ribeirão Preto, entretanto, já ultrapassaram a marca dos 4.000 sacos em termos de média de produção por estabelecimento, o que não teria sido economicamente viável, por exemp̣lo, com tecnologia a recursos seme1hantes àqueles empregados na Região de Sorocaba. Para a produção média de 4.351 sacos de milho, o custo marginal seria, em Ribeirão Preto de $\operatorname{Cr} \$ 70,62$, muito além do preço do produto - se a tecnologia e os recursos produtivos fossem os mesmos disponíveis para o produtor de milho de Sorocaba.

$\vec{E}$ interessante verificar através dos resultados obtidos se a tecnologia de produção de milho adotada pela firma típica de Ribeirão Preto produz as mesmas vantagens econô micas se utilizadas na unidade típica de produção de Sorocaba. Em outras palavras, se o resultado obtido em Ribeirão Preto, com os recursos produtivos atualmente existentes nos estabelecimentos agrícolas, será o mesmo se essa tecnologia for usada em Sorocaba onde os recursos são mais limitados, a julgar pela produção média das firmas e os custos dos fatores fixos de pro dução.

Essa comparação pode ser feita substituindo-se na equação da oferta da firma de Ribeirão Preto o valor da constante $x_{2}$, pelo valor correspondente na equação da oferta da firma típica de Sorocaba.

o custo fixo representa a remuneração dos fatores constantes no curto prazo, que são justamente os disponíveis para os agricultores no momento da adoção de novas técni- 
cas, sem se colocar de imediato a possibilidade de novos inves timentos.

A equação de oferta com os recursos disponíveis na firma de Sorocaba, mas usando-se a tecnologia adotada em Ribeirão Preto, serä:

$$
Y_{S . R P}=P_{y}^{2,4542} \cdot 0,7105^{2,4542} \cdot 0,2496^{3,4542} \cdot 18,607,01^{0,9852}
$$

ou

$$
Y_{S \cdot R P}=57,5647 \cdot P_{y}^{2,4542}
$$

onde $Y_{S}$.RP significa a oferta obtida com a fixação dos recursos produtivos de Sorocaba e a variação da tecnologia para a região de Ribeirão Preto.

A elasticidade desta curva de oferta é igual à da oferta da firma da região de Ribeirão Preto, embora indique custos marginais mais elevados. Mesmo assim, ela revela uma situação de vantagem econômica em comparação com a tecnologia típica de Sorocaba (Fig. 7).

Uma comparação análoga pode ser feita em relação à região de Ribeirão Preto, testando-se uma curva de oferta a nível de estabelecimento agrícola com tecnologia semelhan te à da região de Sorocaba.

A curva de oferta obtida é a seguinte:

$$
\mathrm{Y}_{\mathrm{RP} . \mathrm{S}}=\mathrm{P}_{\mathrm{y}}^{1,0268} \cdot 0,5066^{1,0268} \cdot 0,7082^{2,0268} \cdot 44,629,86^{0,5497}
$$




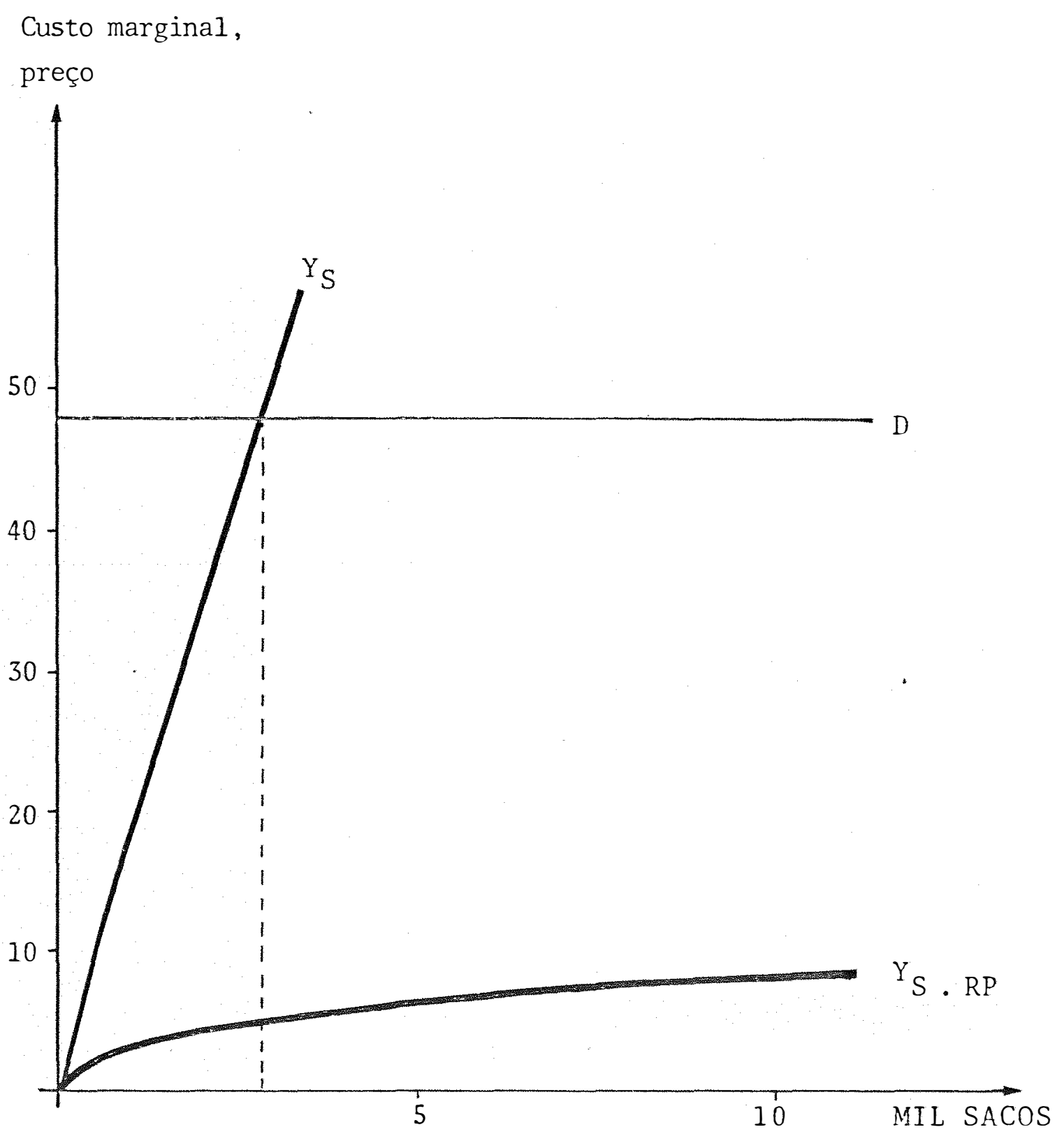

Fig. 7 - ofertas de milho, a curto prazo, da firma típica de Sorocaba $\left(Y_{S}\right)$ e uma simulação utilizando-se a tecno logia de Ribeirão Preto em uma firma típida de Soro

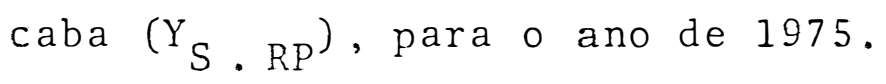


na qual, a redução dos termos constantes a um único termo é:

$$
Y_{R P . S}=88,9089 \cdot P_{y}^{1,0268}
$$

onde $Y_{R P . S}$ significa a oferta obtida com os recursos disponíveis para a firma de Ribeirão Preto e a tecnologia usada na região de Sorocaba.

A tecnologia "moderna" continua sendo a mais vantajosa (Fig. 8) .

Nesta simulação, a técnica "tradicional" apresentou um desempenho melhor na unidade de produção de Ribeirão Preto do que na de Sorocaba, com redução significativa dos cus tos marginais, e possibilitando a expansão da oferta até atingir o nível de produção de 4.800 sacos (contra 2.900 em Soroca ba). Isto quer dizer que ampliando-se os investimentos em mâ quinas, benfeitorias, instalações, terra, etc, na unidade produtora típica de Sorocaba, é possível deslocar a oferta sem a obrigatoriedade de adoção de tecnologias inovadoras.

Sobre as estimativas das curvas de oferta para uma firma típica em cada um dos conjuntos homogêneos, cabe uma observação.

Pode não ocorrer na prätica um grau elevado de homogeneidade entre as observações da amostra como seria desejảvel para que a comparação entre duas firmas representativas fosse mais fiel. Se o desvio padrão revelar umaheterogeneida de entre as firmas ao invés de homogeneidade, a firma deixará 
38 .

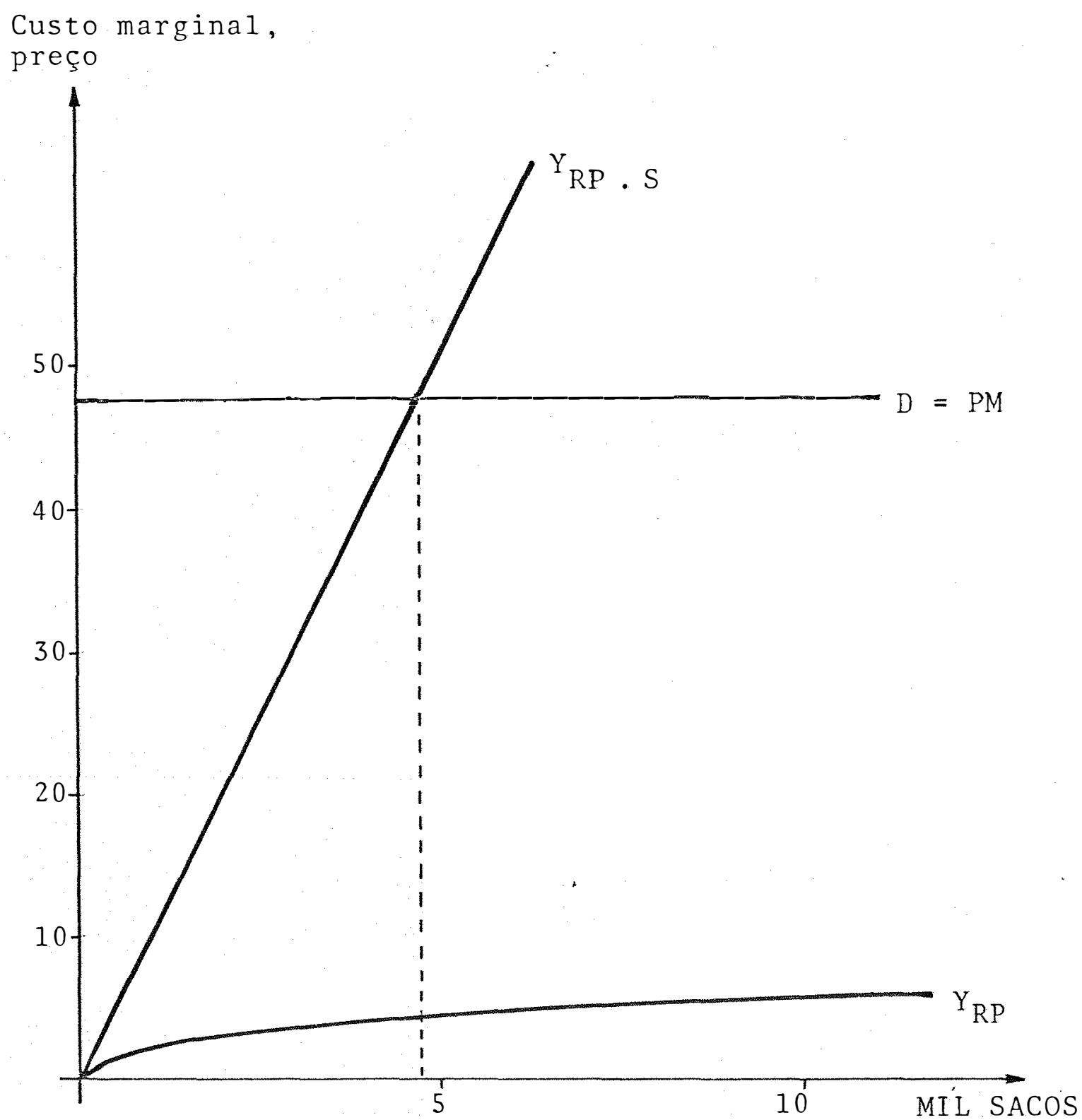

Fig. 8 - Ofertas de milho a curto prazo da firma típica de Ribeirão Preto e uma simulação utilizando-se a mesma tecnologia empregada pela firma de Sorocaba numa firma típica de Ribeirão Preto, para o ano de 1975 . 
de ser típica e os dois conjuntos passam a ser apenas um (se a amplitude de variação das observações for suficiente para englobar os dois conjuntos). Tratando-se, principalmente, de amostras escolhidas ao acaso (aleatórias) esse risco torna-se maior.

A figura 9 é uma tentativa de se desenhar o interivalo de variação da curva de oferta, considerando-se as pos sibilidades de variação no custo fixo encontradas nas duas amostras. Mesmo assim, não se verifica - como pode ser obser vado - uma superposição relevante entre as áreas ocupadas pelas duas curvas de oferta, o que ressalta uma definitiva vanta gem econômica da técnica "moderna" sobre a "tradicional", em termos privados.

O campo de variação da oferta é definido para cada conjunto de observações, pelas equações:

Região de Sorocaba:

$$
\begin{aligned}
& \text { de } Y_{\text {S.MIN }}=12,31 \mathrm{P}_{\mathrm{y}}^{1,0268} \\
& \text { até } \mathrm{Y}_{\text {S.MAX }}=205,57 \mathrm{P}_{\mathrm{y}}^{1,0268}
\end{aligned}
$$

onde $\mathrm{Y}_{\text {S.MIN }}$ representa a oferta da região de Sorocaba no seu nível mais baixo e $\mathrm{Y}_{S . M A X}$ no seu nível mais alto.

Região de Ribeirão Preto:

$$
\begin{aligned}
& \text { de } Y_{R P . M I N}=12,39 \mathrm{P}_{y}^{2,4542} \\
& \text { até } \mathrm{Y}_{\mathrm{RP} . \mathrm{MAX}}=1291,55 \mathrm{P}_{\mathrm{y}}^{2,4542}
\end{aligned}
$$


onde $Y_{R P . M I N}$ representa a oferta da região de Ribeirão Preto no seu nível mais baixo e $Y_{R P . M A X}$ no seu nível mais alto.

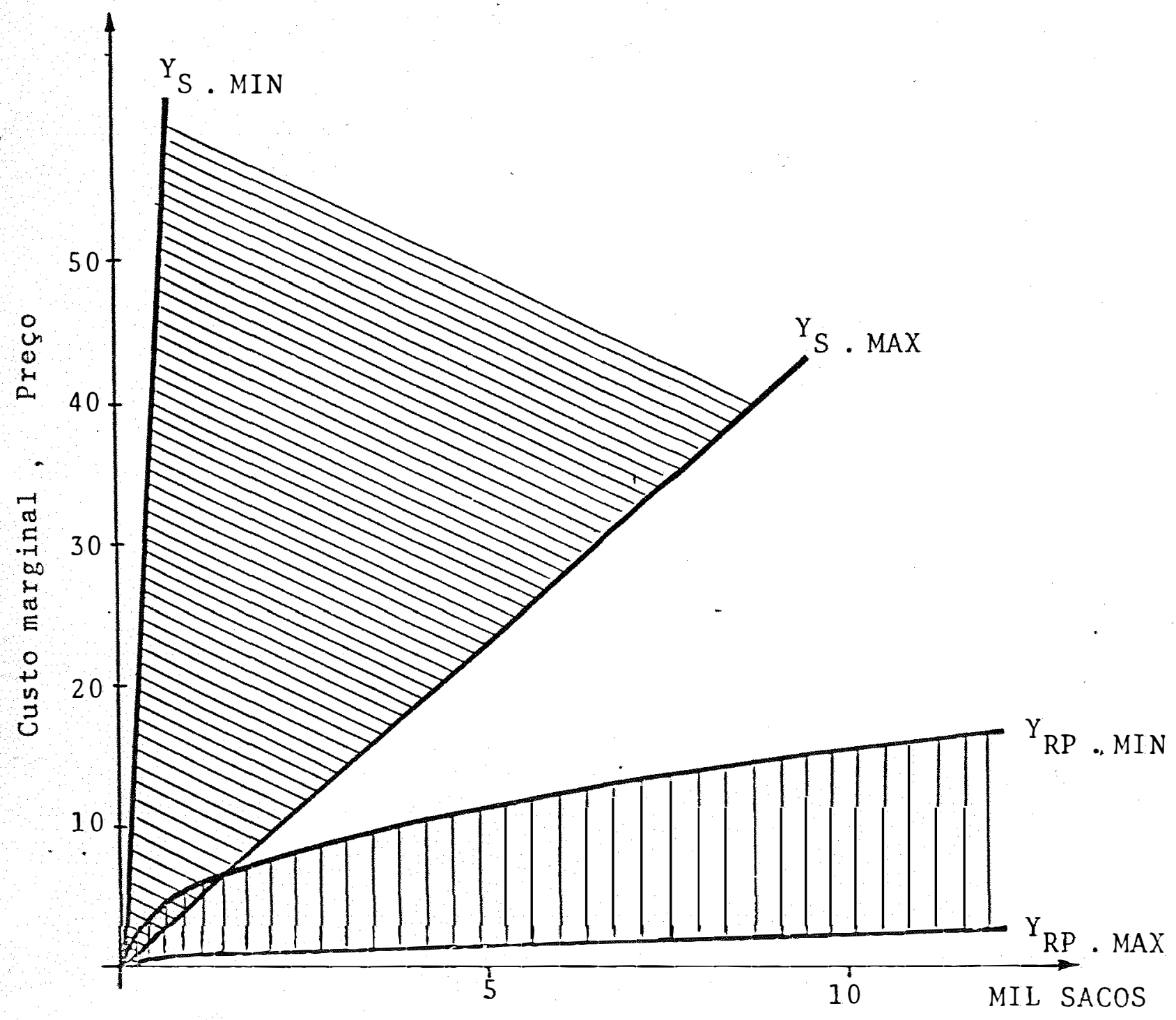

Fig. 9. Intervalos de Variação das ofertas de milho, a curto prazo, da firma para as regiões de Ribeirão Preto e Sorocaba, considerando-se a amplitude de varia ção dos custos fixos observados nas amostras, no ano de 1975. 
6. CONCLUSÕES

O tratamento dos aspectos da modernização do se tor agrícola sob um ângulo interno, microeconômico, de unidade de produção, é sem dúvida uma análise parcial e as conclusões daí extraídas não podem ser definitivas, nem esgotar o assunto. Entretanto, o comportamento da relação entre preços, que propulsiona o mecanismo autocontrolador do processo de difusão das inovações tecnológicas, exerce talvez a influência mais significativa sobre a decisão dos agricultores quanto à modernização do processo produtivo.

A metodologia adotada buscou visualizar o mecanismo que determina ou influencia a adoção de inovações tecnológicas, valorizando os benefícios internos que podem resultar 
da modernização .

A situação das duas curvas de oferta dos dois tipos de produtores e da demanda representada pelo preço revela que o mercado é favorável à modernização das firmas e a ten dência é de modernização das firmas produtoras de milho nas duas regiões estudadas do Estado de São Paulo.

A utilização de modelos econométricos para comparar a eficiência econômica entre diferentes padrões tecnológicos pode contribuir no sentido de um melhor embasamento na formulação de políticas que busquem atingir de maneira diferen ciada distintos ramos ou zonas de produção agrícola, através do conhecimento antecipado da capacidade de resposta a curto prazo, associada às diferentes situações tecnológicas estudadas. 
43.

SUMMARY

This study tries to bring some contribution to discussion about modernization of agriculture in Brazil by analysis of firm supply functions as guidance to technological adoption and innovation.

The objective was to identify homogenous groups of farms in differents stages of technologies estimating a typical supply curve for each group.

The empyrical example is the corn production in two region of the State of São Paulo. The selected regions were Ribeirão Preto that uses a modern technology and Sorocaba when prevails a traditional technology. 
Supply functions derived from production and costs functions provided the basic theoretical framework for the analysis. Information on fixed and variable costs of corn were obtained by Instituto de Economia Agricola (Research about Costs and income Analysis of crops in the State of São Paulo). Comparisons were established between typical firm supply functions adjusted for each region.

The results indicate that modern technology used by Ribeirão Preto farms is more efficient that traditional one from the private point of view. Traditional technology can, therefore, be used with lower efficiency level up to production of 175,56 ton. that is the production level where market price is equal marginal cost.

The Ribeirão Preto firm average production was 261,0 ton. of corn that is more expressive than the firm production obtained from Sorocaba. This could explain a more intensive modernization in Ribeirão Preto region. 
01. CONTADOR, C.R., 1974. Dualismo tecnológico na agricultura: novos comentários. Pesquisa e Planejamento Econômico. Rio de Janeiro, IPEA 4(1):119-138.

02. CONTADOR, C.R., 1974. Tecnologia agrícola em equilíbrio. Otimização privada versus otimização social. II Encon tro anual da Associação Nacional de Centros de PósGraduação em Economia. Belo Horizonte, Mimeo. 28 p.

03. CONTADOR, C.R., 1975. Determinantes de Adoção e mudança tecnológica na agricultura brasileira. XIII Reunião Anual da Sociedade Brasileira de Economia Rural. Curi tiba, Mimeo. $47 \mathrm{p}$. 
04. FGV/IBRE, 1976. Preços recebidos pelos produtores. FGV, Rio de Janeiro. $76 \mathrm{p}$.

05. FIBGE, 1979. Censo Agropecuário Estado de São Paulo, FIBGE, Rio de Janeiro, Tomo 17, Vo1. 1, 2a. parte. 1.695 p.

06. GRAÇA, L.R., E.M.NEVES e E.W.KEHRBERG, 1978. Oferta de so ja: aplicação de uma metodologia usando custos de pro dução. Piracicaba, Dept: de Economia e Sociologia Rural, ESALQ/USP, mimeo. $37 \mathrm{p}$.

07. HAYAMI, Y. e V.E.RUTTAN, 1975. Diferenças de produtividade agrícola entre nações. Desenvolvimento da Agricultura. São Paulo, Edit. Pioneira:77-99.

08. NICHOLLS, W.H., 1973. Paiva e o dủalismo tecnológico na agricultura: um comentário. Pesquisa e Planejamento Econômico. IPEA, Rio de Janeiro, 3(1):15-50.

09. PAIVA, R.M., 1968. O mecanismo de autocontrole no processo de expansão da melhoria técnica da agricultura. Revista Brasileira de Economia. FGV, Rio de Janeiro, $n \div 3: 15-17$.

10. PAIVA, R.M., 1971. Modernização e dualismo tecnológico na agricultura. Pesquisa e Planejamento. IPEA, Rio de Janeiro, 1(2):171-234 . 
11. PAIVA, R.M., 1973. Modernização e dualismo tecnológico na agricultura: resposta aos comentários dos professores Nicholls e Schuh. Pesquisa e Planejamento Econômico. IPEA, Rio de Janeiro, 3(1):95-116.

12. PAIVA, R.M., 1975. Modernização e dualismo tecnológico na agricultura: uma reformulação. Pesquisa e Planejamento Econômico. IPEA, Rio de Janeiro, 5(1):117-163.

13. PASTORE, A.C., E.R.A.ALVES e RIZZIERI,J.A.B., 1974. A inovação induzida e os limites à modernização na agricultura brasileira. XII Reunião Anual da Sociedade Brasileira de Economistas Rurais. Porto Alegre, mimeo. $41 \mathrm{p}$.

14. SCHUH, G.E., 1973. Modernização e dualismo tecnológico na agricultura: um comentário. Pesquisa e Planejamento Econômico. IPEA, Rio de Janeiro, 3(1):51-94.

15. SCHULTZ, T.W., 1965. A transformação da agricultura tradicional. Rio de Janeiro, Zahar. 207 p. 
48 .

A N E X O S 
CUSTO DE PRODUÇÃO POR SACO DE 60kg DE MILHO

COLHIDO NA REGIÃO DE RIBEIRÃO PRETO - SÃO PAULO

JULHO DE 1975

\begin{tabular}{|c|c|c|c|c|}
\hline$\overline{\mathrm{I}} \mathrm{T} E \mathrm{E} S$ & $\operatorname{Cr} \$$ & $\because$ C.F. & $\because \mathrm{C} . \mathrm{V}$. & $\because \mathrm{C} . \mathrm{T}$. \\
\hline Juros sobre o capital fixo & 12,72 & 70,46 & - & 28,83 \\
\hline Arrendamento & 1,03 & 5,68 & - & 2,33 \\
\hline Depreciação & 3,62 & 20,07 & - & 8,21 \\
\hline Impostos e Taxas & 0,25 & 1,32 & - & 0,56 \\
\hline Despesas Gerais & 0,44 & 2,41 & - & 0,99 \\
\hline Custo Fixo & 18,06 & 100,00 & - & 40,92 \\
\hline Mão-de-Obra & 1,44 & - & 5,52 & 3,26 \\
\hline Reparos & 1,59 & - & 6,11 & 3,61 \\
\hline $\begin{array}{l}\text { Alimentação de Animais de } \\
\text { Trabalho }\end{array}$ & 0,03 & - & 0,12 & 0,07 \\
\hline Adubos e Corretivos & 13,08 & - & 50,10 & 29,60 \\
\hline Defensivos & 0,21 & - & 0,81 & 0,48 \\
\hline Sementes & 0,88 & - & 3,37 & 1,99 \\
\hline Embalagem & 1,10 & - & 4,24 & 2,50 \\
\hline Empreita & 2,24 & - & 8,59 & 5,07 \\
\hline $\begin{array}{l}\text { Combustiveis e Lubrifi- } \\
\text { cantes }\end{array}$ & 1,78 & - & 6,83 & 4,04 \\
\hline Funrural & 1,13 & - & 4,32 & 2,56 \\
\hline $\begin{array}{l}\text { Juros sobre o capital } \\
\text { circulante }\end{array}$ & 2,60 & - & 9,99 & 5,90 \\
\hline Custo Variāvel & 26,08 & - & 100,00 & 59,08 \\
\hline 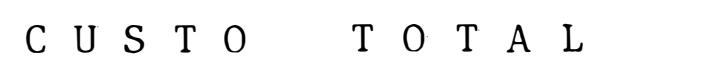 & 44,14 & - & - & 100,00 \\
\hline
\end{tabular}

Fonte: PESQQUISA DIRETA DO I.E.A. 
CUSTO POR SACO DE $60 \mathrm{~kg}$ DE MILHO, COLHIDO NA REGIĀO DE SOROCABA - SÃO PAULO

JULHO DE 1975

\begin{tabular}{|c|c|c|c|c|}
\hline$\overline{\mathrm{I}} \mathrm{T} E \mathrm{~N} S$ & $\operatorname{Cr} \$$ & $\because$ C.F. & $\because$ C.V. & $\because \mathrm{C} . \mathrm{T}$. \\
\hline Juros sobre o capital fixo & 12,77 & 72,38 & - & 26,10 \\
\hline Arrendamento & 1,14 & 6,50 & - & 2,34 \\
\hline Depreciação & 3,20 & 18,11 & - & 6,53 \\
\hline Impostos e Taxas & 0,36 & 2,05 & - & 0,74 \\
\hline Despesas Gerais & 0,17 & 0,96 & - & 0,34 \\
\hline Custo Fixo & 17,64 & 100,00 & - & 36,05 \\
\hline Mão-de-obra & 3,77 & - & 12,04 & 7,70 \\
\hline Reparos & 0,68 & - & 2,17 & 1,39 \\
\hline $\begin{array}{l}\text { Alimentação de Animais de } \\
\text { Trabalho }\end{array}$ & 0,25 & - & 0,81 & 0,52 \\
\hline Adubos e Corretivos & 13,53 & - & 43,25 & 27,66 \\
\hline Defensivos & 0,19 & - & 0,61 & 0,39 \\
\hline Sementes & 0,96 & - & 3,09 & 1,97 \\
\hline Embalagem & 1,83 & - & 5,84 & 3,73 \\
\hline Empreita & 4,80 & - & 15,33 & 9,81 \\
\hline $\begin{array}{l}\text { Combustíveis e Lubrifi- } \\
\text { cantes }\end{array}$ & 2,44 & - & 7,80 & 4,99 \\
\hline Funrural & 0,95 & - & 3,02 & 1,93 \\
\hline $\begin{array}{l}\text { Juros sobre o capital } \\
\text { circulante }\end{array}$ & 1,89 & - & 6,04 & 3,86 \\
\hline Custo Variāvel & 31,29 & - & 100,00 & 63,95 \\
\hline $\mathrm{T} O \mathrm{~T} A \mathrm{~L}$ & 48,93 & - & - & 100,00 \\
\hline
\end{tabular}

Fonte: PESQUISA DIRETA DO I.E.A. 
Produção, Custo Variável, Custo Fixo e Custo Total de Produção para a amostra de produtores de milho de Sorocaba, São Paulo, colheita de 1975 .

\begin{tabular}{crrrr}
\hline Obser & Produção & Custo Variável & Custo Fixo & Custo Total \\
vações & $(\mathrm{Y})$ & $\left(\mathrm{X}_{1}\right)$ & $\left(\mathrm{X}_{2}\right)$ & $($ Cr\$1,00) \\
\hline & & & & \\
01 & 270,00 & $7.603,20$ & $4.299,59$ & $11.902,76$ \\
02 & 300,00 & $13.068,46$ & $5.806,04$ & $18.874,50$ \\
03 & 480,00 & $5.150,31$ & $6.051,27$ & $11.201,58$ \\
04 & 500,00 & $18.158,18$ & $6.485,07$ & $24.643,25$ \\
05 & 500,00 & $13.898,24$ & $7.952,00$ & $21.850,24$ \\
06 & 500,00 & $6.550,88$ & $5.495,49$ & $12.046,37$ \\
07 & 500,00 & $9.454,16$ & $11.124,83$ & $20.578,99$ \\
08 & 570,00 & $24.776,20$ & $7.771,09$ & $32.547,29$ \\
09 & 600,00 & $16.799,36$ & $5.486,53$ & $22.285,89$ \\
10 & 647,00 & $5.321,04$ & $12.443,26$ & $17.764,30$ \\
11 & 650,00 & $20.961,98$ & $14.016,07$ & $34.978,05$ \\
12 & 650,00 & $18.937,02$ & $10.101,09$ & $29.038,11$ \\
13 & 700,00 & $38.261,52$ & $15.843,73$ & $54.105,25$ \\
14 & 725,00 & $19.813,63$ & $12.101,28$ & $31.914,91$ \\
15 & $1.000,00$ & $36.127,63$ & $12.345,43$ & $48.473,06$ \\
16 & $1.000,00$ & $22.178,45$ & $13.394,26$ & $35.572,71$ \\
17 & $1.000,00$ & $25.314,47$ & $19.087,94$ & $44.402,41$ \\
18 & $1.000,00$ & $44.646,14$ & $1.222,41$ & $45.868,55$ \\
19 & $1.200,00$ & $33.104,37$ & $19.934,09$ & $53.038,46$ \\
20 & $1.200,00$ & $32.965,70$ & $9.218,00$ & $42.183,70$ \\
21 & $1.200,00$ & $29.865,61$ & $8.486,91$ & $38.352,52$ \\
22 & $1.200,00$ & $34.372,63$ & $12.026,17$ & $46.398,80$ \\
23 & $1.400,00$ & $38.240,65$ & $19.791,07$ & $58.031,72$ \\
24 & $1.400,00$ & $33.804,29$ & $28.586,55$ & $62.390,84$ \\
25 & $1.500,00$ & $29.798,21$ & $20.104,74$ & $49.902,95$ \\
& & & & continua
\end{tabular}


52.

Continuação

\begin{tabular}{|c|c|c|c|c|}
\hline $\begin{array}{l}\text { Obser } \\
\text { vaçōes }\end{array}$ & $\begin{array}{l}\text { Produção } \\
(Y)\end{array}$ & $\begin{array}{l}\text { Custo Variāve } 1 \\
\qquad\left(x_{1}\right)\end{array}$ & $\begin{array}{l}\text { Custo Fixo } \\
\qquad\left(\mathrm{x}_{2}\right)\end{array}$ & $\begin{array}{l}\text { Custo Total } \\
\qquad(\operatorname{Cr} \$ 1,00)\end{array}$ \\
\hline 26 & $1.600,00$ & $76.977,33$ & $65.844,34$ & $142.821,67$ \\
\hline 27 & $1.620,00$ & $14.954,17$ & $22.824,31$ & $37.778,48$ \\
\hline 28 & $1.700,00$ & $64.240,39$ & $48.879,16$ & $113.119,55$ \\
\hline 29 & $1.700,00$ & $43.714,97$ & $20.725,35$ & $64.440,32$ \\
\hline 30 & $1.800,00$ & $51.877,15$ & $26.593,81$ & $78.470,96$ \\
\hline 31 & $1.800,00$ & $74.219,91$ & $19.140,82$ & $93.360,73$ \\
\hline 32 & $1.850,00$ & $50.456,91$ & $12.074,94$ & $62.531,85$ \\
\hline 33 & $2.000,00$ & $33.605,02$ & $35.490,12$ & $69.095,14$ \\
\hline 34 & $2.000,00$ & $67.400,03$ & $37.690,76$ & $105.090,79$ \\
\hline 35 & $2.040,00$ & $71.270,77$ & $60.912,42$ & $132.183,19$ \\
\hline 36 & $2.500,00$ & $98.253,00$ & $13.938,96$ & $112.191,96$ \\
\hline 37 & $2.500,00$ & $125.297,20$ & $38.751,27$ & $164.048,47$ \\
\hline 38 & $2.500,00$ & $104.186,20$ & $40.810,25$ & $144.996,45$ \\
\hline 39 & $2.539,00$ & $47.131,79$ & $26.276,10$ & $73.407,89$ \\
\hline 40 & $2.700,00$ & $31.243,06$ & $24.938,41$ & $56.181,47$ \\
\hline 41 & $3.600,00$ & $1 \cap 2.218,67$ & $127.498,23$ & $229.716,90$ \\
\hline 42 & $4.000,00$ & $69.998,30$ & $86.597,81$ & $156.596,11$ \\
\hline 43 & $4.500,00$ & $71.488,64$ & $39.386,52$ & $110.875,16$ \\
\hline 44 & $4.500,00$ & $128.389,51$ & $181.227,90$ & $309.617,41$ \\
\hline 45 & $4.750,00$ & $129.216,29$ & $25.085,24$ & $154.301,53$ \\
\hline 46 & $5.400,00$ & $346.758,26$ & $205.056,50$ & $551.814,76$ \\
\hline
\end{tabular}

TOTAL $\quad 78.291,00$

$3.830 .988,03$ 
Produção, Custo Variável, Custo Fixo e Custo Total de Produção, para a amostra de produtores de milho de Ribeirão Preto, São Paulo, colheita de 1975 .

\begin{tabular}{|c|c|c|c|c|}
\hline $\begin{array}{l}\text { Obser } \\
\text { vaçōes }\end{array}$ & $\begin{array}{l}\text { Produção } \\
\text { (Y) }\end{array}$ & $\begin{array}{l}\text { Cus to Variāvel } \\
\qquad\left(\mathrm{x}_{1}\right)\end{array}$ & $\begin{array}{c}\text { Custo Fixo } \\
\left(\mathrm{x}_{2}\right)\end{array}$ & $\begin{array}{l}\text { Cus to Total } \\
(\operatorname{Cr} \$ 1,00)\end{array}$ \\
\hline 01 & 200,00 & $20.944,64$ & $23.200,41$ & $44.145,05$ \\
\hline 02 & 294,00 & $9.298,85$ & $9.715,41$ & $19.014,26$ \\
\hline 03 & 250,00 & $15.893,90$ & $4.653,59$ & $20.547,48$ \\
\hline 04 & 500,00 & $20.318,02$ & $3.889,82$ & $24.207,84$ \\
\hline 05 & 600,00 & $53.780,17$ & $48.077,87$ & $101.858,04$ \\
\hline 06 & 650,00 & $16.023,53$ & $8.991,22$ & $25.014,75$ \\
\hline 07 & 720,00 & $22.270,57$ & $12.404,53$ & $34.675,10$ \\
\hline 08 & 800,00 & $13.279,21$ & $13.862,98$ & $27.142,19$ \\
\hline 09 & 800,00 & $26.856,75$ & $5.446,63$ & $32.303,38$ \\
\hline 10 & 800,00 & $20.272,85$ & $12.300,75$ & $32.573,60$ \\
\hline 11 & 900,00 & $42.681,83$ & $20.574,45$ & $63.256,28$ \\
\hline 12 & 900,00 & $27.310,66$ & $27.699,54$ & $55.010,20$ \\
\hline 13 & 900,00 & $24.059,27$ & $14.006,39$ & $38.065,66$ \\
\hline 14 & $1.000,00$ & $20.123,00$ & $15.472,97$ & $35.595,97$ \\
\hline 15 & $1.000,00$ & $24.232,32$ & $22.496,06$ & $46.728,38$ \\
\hline 16 & $1.100,00$ & $48.952,75$ & $45.191,36$ & $94.144,11$ \\
\hline 17 & $1.170,00$ & $48.215,79$ & $35.431,88$ & $83.647,67$ \\
\hline 18 & $1.200,00$ & $41.739,60$ & $18.846,39$ & $60.585,99$ \\
\hline 19 & $1.200,00$ & $46.560,99$ & $29.931,40$ & $76.492,39$ \\
\hline 20 & $1.200,00$ & $25.416,15$ & $34.221,53$ & $59.637,68$ \\
\hline 21 & $1.200,00$ & $78.815,33$ & $97.779,26$ & $176.594,59$ \\
\hline 22 & $1.200,00$ & $32.406,80$ & $34.966,55$ & $67.373,35$ \\
\hline 23 & $1.260,00$ & $20.233,80$ & $27.814,84$ & $48.048,64$ \\
\hline 24 & $1.500,00$ & $47.384,40$ & $17.845,79$ & $65.230,19$ \\
\hline 25 & $1.650,00$ & $51.315,49$ & $46.135,53$ & $\begin{array}{c}97.451,02 \\
\text { continua }\end{array}$ \\
\hline
\end{tabular}


54.

Continuação

\begin{tabular}{|c|c|c|c|c|}
\hline $\begin{array}{l}\text { Obser } \\
\text { vaçōes }\end{array}$ & $\begin{array}{l}\text { Produção } \\
(Y)\end{array}$ & $\begin{array}{l}\text { Custo Variảvel } \\
\qquad\left(x_{1}\right)\end{array}$ & $\begin{array}{l}\text { Custo Fixo } \\
\qquad\left(\mathrm{x}_{2}\right)\end{array}$ & $\begin{array}{l}\text { Custo Total } \\
(\operatorname{Cr} \$ 1,00)\end{array}$ \\
\hline 26 & $2.000,00$ & $49.063,93$ & $27.073,54$ & $76.137,47$ \\
\hline 27 & $2.000,00$ & $72.640,96$ & $73.324,89$ & $145.965,85$ \\
\hline 28 & $2.100,00$ & $107.002,88$ & $37.951,42$ & $144.954,30$ \\
\hline 29 & $2.200,00$ & $49.382,25$ & $79.457,80$ & $128.840,05$ \\
\hline 30 & $2.300,00$ & $41.232,64$ & $11.753,92$ & $52.986,56$ \\
\hline 31 & $2.800,00$ & $36.210,02$ & $25.234,58$ & $61.444,60$ \\
\hline 32 & $3.000,00$ & $62.562,77$ & $43.063,90$ & $105.626,67$ \\
\hline 33 & $3.200,00$ & $238.986,38$ & $28.045,48$ & $267.031,86$ \\
\hline 34 & $3.500,00$ & $229.284,85$ & $33.814,08$ & $263.098,93$ \\
\hline 35 & $3.650,00$ & $61.637,80$ & $41.471,11$ & $103.108,91$ \\
\hline 36 & $4.000,00$ & $91.873,72$ & $69.626,24$ & $161.499,96$ \\
\hline 37 & $4.000,00$ & $98.582,87$ & $47.129,61$ & $145.712,98$ \\
\hline 38 & $4.200,00$ & $113.207,71$ & $54.361,77$ & $167.569,48$ \\
\hline 39 & $4.200,00$ & $350.670,20$ & $284.863,90$ & $635.534,10$ \\
\hline 40 & $4.410,00$ & $77.477,89$ & $59,030,69$ & $136.508,58$ \\
\hline 41 & $4.500,00$ & $277.657,61$ & $146.737,93$ & $424.395,54$ \\
\hline 42 & $4.627,00$ & $209.670,37$ & $68.214,45$ & $277.884,82$ \\
\hline 43 & $4.800,00$ & $167.725,94$ & $159.718,17$ & $327.444,11$ \\
\hline 44 & $5.000,00$ & $124.298,83$ & $100.521,38$ & $224.820,21$ \\
\hline 45 & $5.600,00$ & $162.964,35$ & $87.488,37$ & $250.452,72$ \\
\hline 46 & $6.000,00$ & $203.887,38$ & $88.466,19$ & $292.353,57$ \\
\hline 47 & $6.000,00$ & $113.757,46$ & $98.578,42$ & $212.335,88$ \\
\hline 48 & $7.800,00$ & $95.670,38$ & $79.407,66$ & $175.078,04$ \\
\hline 49 & $8.000,00$ & $306.263,19$ & $242.299,20$ & $548.562,39$ \\
\hline 50 & $8.184,00$ & $66.474,96$ & $95.025,09$ & $161.500,05$ \\
\hline 51 & $8.670,00$ & $151.4 .89,12$ & $119.604,72$ & $271.093,84$ \\
\hline 52 & $9.000,00$ & $276.227,62$ & $57.299,37$ & $333.526,99$ \\
\hline 53 & $9.500,00$ & $156.607,94$ & $285.563,83$ & $\begin{array}{c}442.171,77 \\
\text { continua }\end{array}$ \\
\hline
\end{tabular}


Continuação

\begin{tabular}{lcccc}
\hline $\begin{array}{c}\text { Obse } \\
\text { vações }\end{array}$ & $\begin{array}{c}\text { Produção } \\
(\mathrm{Y})\end{array}$ & $\begin{array}{c}\text { Custo Variävel } \\
\left(\mathrm{X}_{1}\right)\end{array}$ & $\begin{array}{c}\text { Custo Fixo } \\
\left(\mathrm{X}_{2}\right)\end{array}$ & $\begin{array}{c}\text { Custo Tota1 } \\
(\text { Cr\$1,00) }\end{array}$ \\
\hline 54 & $9.825,00$ & $137.826,32$ & $51.844,69$ & $189.671,01$ \\
55 & $10.000,00$ & $229.278,52$ & $133.247,88$ & $362.526,40$ \\
56 & $10.000,00$ & $205.627,04$ & $330.343,30$ & $535.970,34$ \\
57 & $13.400,00$ & $260.219,47$ & $164.143,38$ & $424.362,85$ \\
58 & $17.250,00$ & $400.311,17$ & $241.849,34$ & $642.160,51$ \\
59 & $40.000,00$ & $1.031 .615,55$ & $434.765,43$ & $1.466 .380,98$ \\
& & & & \\
\hline
\end{tabular}

